Virginia Commonwealth University VCU Scholars Compass

\title{
Genomewide Association Study of Alcohol Dependence Identifies Risk Loci Altering Ethanol- Response Behaviors in Model Organisms
}

Amy E. Adkins

Virginia Commonwealth University

Laura M. Hack

Virginia Commonwealth University

Tim B. Bigdeli

Virginia Commonwealth University

See next page for additional authors

Follow this and additional works at: http://scholarscompass.vcu.edu/psych_pubs

Part of the Psychiatry and Psychology Commons

Copyright (C) 2017 by the Research Society on Alcoholism.

\section{Downloaded from}

http://scholarscompass.vcu.edu/psych_pubs/73

This Article is brought to you for free and open access by the Dept. of Psychiatry at VCU Scholars Compass. It has been accepted for inclusion in Psychiatry Publications by an authorized administrator of VCU Scholars Compass. For more information, please contact libcompass@vcu.edu. 


\section{Authors}

Amy E. Adkins, Laura M. Hack, Tim B. Bigdeli, Vernell S. Williamson, G. Omari McMichael, Mohammed Mamdani, Alexis C. Edwards, Fazil Aliev, Robin F. Chan, Poonam Bhandari, Richard C. Raabe, Joseph T. Alaimo, GinaMari G. Blackwell, Arden Moscati, Ryan S. Poland, Benjamin Rood, Diana G. Patterson, Dermot Walsh, Collaborative Study of the Genetics of Alcoholism Consortium, John B. Whitfield, Gu Zhu, Grant W. Montgomery, Anjali K. Henders, Nicholas G. Martin, Andrew C. Heath, Pamela A.F. Madden, Josef Frank, Monika Ridinger, Norbert Wodarz, Michael Soyka, Peter Zill, Marcus Ising, Markus M. Nöthen, Falk Kiefer, Marcella Rietschel, the German Study of the Genetics of Addiction Consortium, Joel Gelernter, Richard Sherva, Ryan Koesterer, Laura Almasy, Hongyu Zhao, Henry R. Kranzler, Lindsay A. Farrer, Brion S. Maher, Carol A. Prescott, Danielle M. Dick, Silviu A. Bacanu, Laura D. Mathies, Andrew G. Davies, Vladimir I.

Vladimirov, Mike Grotewiel, M. Scott Bowers, Jill C. Bettinger, Bradley T. Webb, Michael F. Miles, Kenneth S. Kendler, and Brien P. Riley 


\title{
Genomewide Association Study of Alcohol Dependence Identifies Risk Loci Altering Ethanol-Response Behaviors in Model Organisms
}

\begin{abstract}
Amy E. Adkins*, Laura M. Hack*, Tim B. Bigdeli*, Vernell S. Williamson, G. Omari McMichael, Mohammed Mamdani, Alexis C. Edwards (D), Fazil Aliev, Robin F. Chan, Poonam Bhandari, Richard C. Raabe, Joseph T. Alaimo, GinaMari G. Blackwell, Arden Moscati, Ryan S. Poland, Benjamin Rood, Diana G. Patterson, Dermot Walsh, Collaborative Study of the Genetics of Alcoholism Consortium ${ }^{\dagger}$, John B. Whitfield, Gu Zhu, Grant W. Montgomery, Anjali K. Henders, Nicholas G. Martin, Andrew C. Heath, Pamela A.F. Madden, Josef Frank, Monika Ridinger, Norbert Wodarz, Michael Soyka, Peter Zill, Marcus Ising, Markus M. Nöthen, Falk Kiefer, Marcella Rietschel, the German Study of the Genetics of Addiction Consortium, Joel Gelernter, Richard Sherva, Ryan Koesterer, Laura Almasy, Hongyu Zhao, Henry R. Kranzler, Lindsay A.

Farrer, Brion S. Maher, Carol A. Prescott, Danielle M. Dick, Silviu A. Bacanu, Laura D.

Mathies, Andrew G. Davies, Vladimir I. Vladimirov, Mike Grotewiel, M. Scott Bowers, Jill C. Bettinger, Bradley T. Webb, Michael F. Miles, Kenneth S. Kendler, Brien P. Riley iD
\end{abstract}

From the Virginia Commonwealth University Alcohol Research Center ( $A E A, L M H, V S W, G O M, M M, A C E, F A, R F C, A M, D M D, S A B$, $A G D, V I V, M G, M S B, J C B, B T W, M F M, K S K, B P R$ ), Virginia Commonwealth University, Richmond, Virginia; Department of Psychiatry (AEA, $L M H, T B B, V S W, G O M, M M, A C E, F A, A M, R S P, B R, D M D, S A B, V I V, M S B, B T W, K S K, B P R)$, Virginia Commonwealth University, Richmond, Virginia; Department of Human \& Molecular Genetics (RFC, PB, DMD, MG, MFM, KSK, BPR), Virginia Commonwealth University, Richmond, Virginia; Department of Pharmacology \& Toxicology (RCR, JTA, GGB, LDM, AGD, MSB, JCB, MFM), Virginia Commonwealth University, Richmond, Virginia; Shaftesbury Square Hospital (DGP), Belfast, United Kingdom; Health Research Board (DW), Dublin 2, Ireland; Genetic Epidemiology (JBW, GZ, GWM, AKH, NGM), QIMR Berghofer Medical Research Institute, Royal Brisbane and Women's Hospital, Brisbane, Qld, Australia; Department of Psychiatry (ACH, PAFM), Washington University School of Medicine, St. Louis, Missouri; Department of Genetic Epidemiology in Psychiatry (JF, MR), Central Institute of Mental Health, Medical Faculty Mannheim/Heidelberg University, Mannheim, Germany; Department of Addictive Behavior and Addiction Medicine (FK), Central Institute of Mental Health, Medical Faculty Mannheim/Heidelberg University, Mannheim, Germany; Department of Psychiatry (MR, NW), University Hospital Regensburg, University of Regensburg, Regensburg, Germany; Privatklinik Meiringen (MS), Meiringen, Switzerland; Department of Psychiatry and Psychotherapy (MS, PZ), University of Munich, Munich, Germany; Department of Molecular Psychology (MI), Max-Planck-Institute of Psychiatry, Munich, Germany; Department of Genomics (MMN), Life \& Brain Center, University of Bonn, Bonn, Germany; Institute of Human Genetics (MMN), University of Bonn, Bonn, Germany; German Center for Neurodegenerative Diseases (DZNE) (MMN), University of Bonn, Bonn, Germany; Department of Psychiatry (JG), Yale University School of Medicine, New Haven, Connecticut; Department of Neurobiology (JG), Yale University School of Medicine, New Haven, Connecticut; Department of Genetics (JG, HZ), Yale University School of Medicine, New Haven, Connecticut; Department of Biostatistics (HZ), Yale University School of Medicine, New Haven, Connecticut; Department of Psychiatry (JG, LAF), VA CT Healthcare Center, West Haven, Connecticut; Department of Genetics (LA), Texas Biomedical Research Institute, San Antonio, Texas; Department of Psychiatry (HRK), Treatment Research Center, University of Pennsylvania Perelman School of Medicine, Philadelphia, Pennsylvania; Philadelphia VA Medical Center (HRK), VISN 4 MIRECC, Philadelphia, Pennsylvania; Department of Medicine (Biomedical Genetics) (RS, RK, LAF), Boston University School of Medicine, Boston, Massachusetts; Department of Neurology (LAF), Boston University School of Medicine, Boston, Massachusetts; Department of Ophthalmology (LAF), Boston University School of Medicine, Boston, Massachusetts; Department of Epidemiology (LAF), Boston University School of Public Health, Boston, Massachusetts; Department of Biostatistics (LAF), Boston University School of Public Health, Boston, Massachusetts; Department of Mental Health (BSM), Johns Hopkins Bloomberg School of Public Health, Baltimore, Maryland; Department of Psychology (CAP), University of Southern California, Los Angeles, California; Lieber Institute for Brain Development (VIV), Johns Hopkins University, Baltimore, Maryland; and Center for Biomarker Research and Personalized Medicine (VIV), School of Pharmacy, Virginia Commonwealth University, Richmond, Virginia.

Received for publication August 20, 2016; accepted February 16, 2017.

Reprint requests: Brien P. Riley, PhD, Virginia Institute for Psychiatric and Behavioral Genetics, Virginia Commonwealth University, P.O. Box 980424, Richmond, VA 23298-0424; Tel.: 804-828-8083; Fax: 804-828-1471; E-mail: brien.riley@vcuhealth.org

Present address (AEA, FA, DMD): Department of Psychology, Virginia Commonwealth University, PO Box 842018, Richmond, VA, 232842018.

Present address (AEA,DMD): College Behavioral and Emotional Health Institute, Virginia Commonwealth University, PO Box 842018, Richmond, $V A, 23284-2018$.

Present address (MSB): Faulk Center for Molecular Therapeutics, Department of Biomedical Engineering, Northwestern University, 1801 Maple Ave, Evanston, IL 60201.

* These authors contributed equally to this work.

'The members of "Collaborative Study of the Genetics of Alcoholism Consortium" and "the German Study of the Genetics of Addiction Consortium" details are given in Acknowledgments.

Copyright $(2017$ by the Research Society on Alcoholism.

DOI: 10.1111/acer.13362 
Background: Alcohol dependence (AD) shows evidence for genetic liability, but genes influencing risk remain largely unidentified.

Methods: We conducted a genomewide association study in 706 related AD cases and 1,748 unscreened population controls from Ireland. We sought replication in 15,496 samples of European descent. We used model organisms (MOs) to assess the role of orthologous genes in ethanol (EtOH)response behaviors. We tested 1 primate-specific gene for expression differences in case/control postmortem brain tissue.

Results: We detected significant association in COL6A3 and suggestive association in 2 previously implicated loci, KLF12 and $R Y R 3$. None of these signals are significant in replication. A suggestive signal in the long noncoding RNA LOC339975 is significant in case:control meta-analysis, but not in a population sample. Knockdown of a COL6A3 ortholog in Caenorhabditis elegans reduced EtOH sensitivity. Col6a3 expression correlated with handling-induced convulsions in mice. Loss of function of the KLF12 ortholog in C. elegans impaired development of acute functional tolerance (AFT). Klf12 expression correlated with locomotor activation following EtOH injection in mice. Loss of function of the $R Y R 3$ ortholog reduced EtOH sensitivity in C. elegans and rapid tolerance in Drosophila. The ryanodine receptor antagonist dantrolene reduced motivation to self-administer EtOH in rats. Expression of LOC339975 does not differ between cases and controls but is reduced in carriers of the associated rs 11726136 allele in nucleus accumbens (NAc).

Conclusions: We detect association between AD and COL6A3, KLF12, RYR3, and LOC339975. Despite nonreplication of $C O L 6 A 3, K L F 12$, and $R Y R 3$ signals, orthologs of these genes influence behavioral response to $\mathrm{EtOH}$ in $\mathrm{MOs}$, suggesting potential involvement in human EtOH response and AD liability. The associated LOC339975 allele may influence gene expression in human NAc. Although the functions of long noncoding RNAs are poorly understood, there is mounting evidence implicating these genes in multiple brain functions and disorders.

Key Words: Alcohol Dependence, COL6A3, KLF12, LOC339975, RYR3.

A LCOHOL DEPENDENCE (AD) is a major public health burden with substantial costs for individuals and societies (Rice, 1999). Despite robust evidence for genetic influences on risk (Cotton, 1979; Prescott et al., 2005a; Sigvardsson et al., 1996) and heritability estimates of $\sim 50 \%$ (Ystrom et al., 2011), the genes influencing AD risk remain largely unidentified.

Prior genomewide association studies (GWAS) of AD and alcohol-related phenotypes in European samples detected novel signals in the PECR (Treutlein et al., 2009), AUTS2 (Schumann et al., 2011), and uncharacterized c15orf53 (Wang et al., 2013) genes. None of these novel signals were replicated. Two independent signals were detected and replicated around the long-standing candidate gene $A D H 1 B$ (Frank et al., 2012; Gelernter et al., 2014). Three studies of Asian subjects identified signals at $A L D H 2$ (Baik et al., 2011; Quillen et al., 2014) and the $A D H 1 B$ functional variant H47R (rs1229984) (Park et al., 2013), likely due to the frequencies of functional $A D H$ and $A L D H$ alleles in Asian populations.

To identify genes influencing alcohol-related phenotypes, we conducted a GWAS of AD. To maximize power, we studied an ethnically homogeneous sample of cases, affected siblings, and unscreened controls from Ireland, correcting for relatedness and lack of control screening analytically. We sought replication in 15,496 subjects of European descent (6,742 case/controls and 8,754 population samples).

Well-developed experimental approaches can test directly whether changes in candidate genes impact behavioral response to ethanol $(\mathrm{EtOH})$ in vertebrate $(\mathrm{Crabbe}, 2002)$ and invertebrate (Grotewiel and Bettinger, 2015) model organisms (MOs). Orthologs of genes that affect simple EtOH responses in invertebrates also affect more complex EtOH responses in mammals, including measures of sensitivity and voluntary drinking (Bhandari et al., 2012; Kapfhamer et al., 2008; Liu et al., 2008). This approach has previously been successful in demonstrating functional relevance of genes implicated by GWAS in EtOH-response behaviors (Schumann et al., 2011).

To provide functional support for GWAS candidates, we tested whether perturbation of orthologous genes alters behavioral response to EtOH in Caenorhabditis elegans and/ or Drosophila, depending on the presence of orthologous genes and the availability of genetic reagents and information. In vertebrate MO, we analyzed correlations between candidate gene expression and alcohol phenotypes bioinformatically in curated archival data from recombinant inbred (BXD) mouse lines and we tested the effect of pharmacological antagonism of 1 candidate gene product on motivation to self-administer EtOH in rats after chronic EtOH exposure. For 1 candidate gene with no ortholog outside of primates, we tested for expression differences in alcohol-dependent and control human postmortem brain tissue stratified by clinical status or genotype.

\section{MATERIALS AND METHODS}

\section{GWAS Discovery Sample}

Participants in the Irish Affected Sib Pair Study of Alcohol Dependence (IASPSAD) were recruited in Ireland and Northern Ireland between 1998 and 2002 (Prescott et al., 2005b). Briefly, probands were ascertained in community alcoholism treatment facilities and public and private hospitals. Probands were eligible for inclusion if they met DSM-IV criteria (American Psychiatric Association, 1994) for lifetime AD and if all 4 grandparents had 
been born in Ireland, Northern Ireland, Scotland, Wales, or England. Probands, siblings, and parents were interviewed by clinically trained research interviewers, most of whom had extensive clinical experience with alcoholism. We assessed lifetime history of AD using a modified version of the Semi-Structured Assessment of the Genetics of Alcoholism interview, version II (Bucholz et al., 1994), demographic characteristics, other comorbid conditions, alcohol-related traits, personality features, and clinical records. All participants provided informed consent. We included 815 probands and siblings in genotyping.

A total of 2,048 DNA samples from healthy, unpaid volunteers donating blood at the Irish Blood Transfusion Service and obtained from the Trinity Biobank at Trinity College Dublin were used as controls. Biobank controls were eligible if they denied any problems with alcohol or history of mental illness and if all 4 grandparents had been born in Ireland, Northern Ireland, Scotland, Wales, or England. Because of the sample source, controls were not formally screened for AD, but the lack of screening was addressed analytically (see GWAS Statistical Analyses). Information about age and sex was available for these subjects.

\section{GWAS Genotyping, Quality Control, and Imputation}

Genomic DNAs passing quality control (QC) standards were genotyped on Affymetrix v6.0 SNP arrays (Affymetrix, Santa Clara, CA). All arrays included in analysis passed standard QC measures. Genotypes were called using BEAGLECALL (Browning and $\mathrm{Yu}, 2009$ ), followed by rigorous genotype QC. We imputed the 1000 Genomes Project (1000 Genomes Project Consortium, 2010) April 2012 integrated variant reference panel of 36.5 million simple nucleotide polymorphisms (SNPs) using IMPUTE2 (Howie et al., 2009). We converted posterior genotypic probabilities to allelic dosages using GenABEL (Aulchenko et al., 2007). After postimputation QC, 8,344,348 SNPs were available for analysis. Complete details of array, SNP and individual QC, BEAGLECALL genotyping, imputation, and postimputation QC and sample power are included in Appendix S1 and Figs S1-S4.

\section{GWAS Statistical Analyses}

We tested individual SNPs for association by Modified QuasiLikelihood Score (MQLS) (Thornton and McPeek, 2007) because MQLS accepts genotypes in postimputation dosage format and can account for subject relatedness by using a kinship matrix calculated from pedigree data. Unscreened Biobank controls were coded as phenotype unknown. We included an estimated sex-weighted $8.9 \%$ population $\mathrm{AD}$ prevalence derived from population (Hasin et al., 2007) and unpaid Dutch blood donor (Atsma et al., 2011) data to account for lack of control screening. Varying this estimate from $0 \%$ to $12 \%$ gave a similar $p$-value distribution for all prevalence estimates. MQLS cannot include covariates. We used a threshold of $p \leq 5 \times 10^{-8}$ for genomewide significant (GWS) results. Odds ratios were not calculated due to the nonindependence of related case alleles. Secondary analytic approaches for gene-based, network, and geneset analyses are described in Supplementary Methods in Appendix S1.

\section{Selection for Further Study}

We calculated false discovery rate (FDR) $q$-values (Storey and Tibshirani, 2003) for all SNPs to select loci for further study. For replication and secondary analysis of discovery data, we used a threshold $q<0.3\left(p<1 \times 10^{-5}\right.$ for our $p$-value distribution, $30 \%$ of results are false discoveries) to maximize discovery potential. For functional studies, we included any loci achieving GWS signals in discovery or replication (COL6A3, LOC339975) and any loci with both $q<0.1(10 \%$ of results are false discoveries) and prior evidence of involvement in EtOH phenotypes from human and/or MO studies (KLF12, RYR3).

\section{Assessment of Variants for Potential Functional Impact}

For variants with $q<0.1$, we assessed variant potential to impact function either directly or via linkage disequilibrium (LD) with other variants using GWAS3D (Li et al., 2013). GWAS3D provides an adjusted $p$-value from Fisher's combined probability test incorporating the GWAS evidence of genetic association with evidence that the variant alters (i) coding or (ii) conserved sequence, or (iii) sites of long-range interactions, (iv) binding energy for known transcription factors or lies within (v) promoter, (vi) enhancer, or (vii) insulator elements from ENCODE and other published sources.

\section{GWAS Replication}

We conducted replication analyses in $N=15,496$ European subjects from 3 AD case-control samples (Edenberg et al., 2010; Frank et al., 2012; Gelernter et al., 2014; Treutlein et al., 2009) and 1 population sample (Heath et al., 2011). Details of the individual samples, genotyping, and imputation are provided in Appendix S1. We conducted look-up analysis of replication SNPs in each sample and meta-analysis of all replication SNPs first in the 4 ascertained casecontrol samples, then adding the unascertained population sample, for which AD diagnoses were derived rather than directly assessed (Heath et al., 2011), using METAL (Willer et al., 2010). We weighted meta-analyses by sample size and direction of effect because MQLS does not generate standard errors. Many markers are nonindependent due to LD, so we assessed the 274 replication SNPs for independence using SNAP (Johnson et al., 2008) to determine the number of independent tests.

\section{Invertebrate MO Studies}

C. elegans Studies. A single, continuous acute exposure of C. elegans to $400 \mathrm{mM}$ exogenous EtOH yields an internal concentration of 40 to $50 \mathrm{mM}$ (Alaimo et al., 2012) ( $\sim 200 \mathrm{mg} / \mathrm{dl}$, within the range observed in humans after heavy drinking (Bond et al., 2010)). A concentration-dependent slowing of locomotion at 10-minute exposure (measuring initial sensitivity) is followed at $\sim 30$ minutes by an increase in speed of locomotion (measuring AFT) (Davies et al., 2003, 2004) despite an increase in the internal tissue concentration of EtOH (Alaimo et al., 2012). Both measures can be independently affected by the loss of individual genes (Bettinger et al., 2012; Bhandari et al., 2012; Davies et al., 2003, 2004; Kapfhamer et al., 2008; Mathies et al., 2015).

C. elegans Strains - C. elegans strains were maintained as previously described (Brenner, 1974). Strains used in these studies were wild-type N2 (var. Bristol), RB1603 klf-3(ok1975), TR2170 unc-68 (r1161), and TR2171 unc-68(r1162).

RNAi Treatment-RNA interference (RNAi) induction and locomotion assays were performed as previously described (Kamath et al., 2001). Briefly, cultures of bacteria containing RNAi vectors corresponding to genes C16E9.1, C18H7.1, cutl-23, or empty vector (L4440) (Geneservice, Cambridge, UK) were plated on nematode growth media (NGM) plates with $1 \mathrm{mM} \mathrm{IPTG,}$ and allowed to grow at room temperature for 24 hours. Three to 5 fourth larval stage wild-type N2 worms were placed on the seeded plates and incubated at $20^{\circ} \mathrm{C}$ and allowed to produce $\mathrm{F} 1$ progeny, which were maintained on RNAi cultures to adulthood. First-day adult F1 progeny were collected and subjected to behavioral analysis. 
Locomotion Tracking-Locomotion was assayed as previously described (Bettinger et al., 2012). Ten worms for each strain were tested in each assay, and we calculate the average of the speeds of the 10 worms in each iteration of the assay $(n=1)$. Comparisons were only made of animals tested simultaneously on the same plates. Briefly, NGM-containing plates were dried for 2 hours with lids off at $37^{\circ} \mathrm{C}$, and then, copper rings were embedded in the surface of the plate to act as corrals. EtOH was added to the plates to a final concentration of 0 or $400 \mathrm{mM}$, the plates were sealed, and the EtOH was allowed to equilibrate for 2 hours. Worms were placed in the corrals and 2-minute movies were captured at 10 and 30 minutes of exposure using a Retiga 4000R camera (QImaging, Surrey, BC, Canada) on an Olympus SZX-7 microscope (Center Valley, PA). Movies were analyzed using ImagePro Plus (6.2) (MediaCybernetics, Rockville, MD) software. We derived 2 measures of EtOH response: initial sensitivity (depression of speed of locomotion at 10-minute exposure compared to the same strain untreated) and AFT (increase in speed at 30-minute exposure compared to the same strain at 10 minutes).

Statistical Analysis-Comparisons were made of animals tested in identical conditions. Relative speeds (treated/untreated $\times 100$ ) were used in comparisons. We used Prism 5.0 software (GraphPad, La Jolla, CA) to perform 2-way ANOVA comparisons across time of EtOH exposure and genotype with Bonferroni post hoc comparisons at each time point to determine differences between genotypes. Development of AFT was tested using a paired 2-tailed $t$-test.

Drosophila Studies. Only 1 candidate locus ( $R Y R 3)$ had both a Drosophila ortholog and genetic reagents available. Detailed methods for Drosophila studies are provided in Supplementary Materials and Methods in Appendix S1.

\section{Mammalian MO Studies}

Mouse Studies. We queried selected candidate genes for localization to EtOH behavioral quantitative trait locus (QTL) intervals using the Mouse Genome Informatics (MGI) tool set. We queried published expression microarray and EtOH behavioral response data sets within the curated GeneNetwork web-based resource of genetic, phenotypic, and genomic data for evidence that basal candidate gene expression correlated with measured EtOH behavioral phenotypes in $\mathrm{C} 57 \mathrm{BL} / 6 \mathrm{~J} \times \mathrm{DBA} / 2 \mathrm{~J}$ BXD mouse lines. All expression data were from Affymetrix M430 microarrays (Affymetrix, Santa Clara, CA). We included saline or air-treated BXD control whole brain (GN113), nucleus accumbens (NAc) (GN156), prefrontal cortex (PFC) (GN135), and ventral tegmental area (VTA) (GN228) (Wolen et al., 2012).

We used the single Col6a3 probeset (1424131_at_A). We selected the most representative probeset based on Gene $\bar{N}$ etwork quality scores for Ryr3 (1427427_at_A) and Klf12 (1455521_at; we also assessed the better of the 2 probesets showing Klf12 EtOH response (Wolen et al., 2012), 1439847_s_at). Robust multi-array average normalized expression data were used for Spearman rank correlation analyses with EtOH behavioral phenotypes. Identifiers of probesets and phenotypes used for specific analyses are shown in Results and in Fig. 5. Expression and phenotype data archived in GeneNetwork were produced in different laboratories and at different times; as a result, the N of BXD lines tested in our analyses varies across the tissues and phenotypes analyzed. We use the GeneNetwork default setting to retrieve the top 1,000 correlations for each probeset $\times$ tissue pair.

A total of 5,134 traits are present in GeneNetwork, but they are not all independent because of both the multiple related measures made within studies and the partial overlap of BXD lines used between studies. GeneNetwork developers suggest that
Bonferroni correction for 200 independent traits approximates an FDR of 0.2 based on data in (Wang et al., 2016)). We apply a more stringent correction for 2,000 independent tests to maintain a conservative significance threshold of $0.05 / 2,000=2.5 \mathrm{E}$ 05 .

Rat Studies. We studied the effect of pharmacological antagonism of ryanodine receptors on EtOH self-administration in rats. Detailed methods for this single rat study are provided in Supplementary Materials and Methods in Appendix S1.

\section{Human Postmortem Studies}

PFC and NAc tissues from 41 AD cases and 41 controls were provided by the New South Wales Tissue Resource Centre. Age, sex, ethnicity, brain weight, brain $\mathrm{pH}$, postmortem interval (PMI), tissue hemisphere, cause of death, blood toxicology, smoking status, neuropathology, and liver pathology were provided for each subject. Confounding effects of all these covariates were controlled by analysis of covariance (ANCOVA; Table S7). Total RNA was isolated from $100 \mathrm{mg}$ frozen tissue using the mirVana-PARIS kit (Life Technologies, Carlsbad, CA) following manufacturer's protocols. RNA concentration was measured using the Quant-iT Broad Range RNA Assay kit (Life Technologies). The RNA integrity number (RIN) was measured on the Agilent 2100 Bioanalyzer (Agilent Technologies, Inc., Santa Clara, CA). Quantitative real-time PCR (qRT-PCR) analyses were performed as previously described using SYBR Green (Riley et al., 2010) with primers spanning the LOC339975 exon 2 to 3 junction. Samples with missing genotypes and outliers $( \pm 2$ standard deviations [SD] from the mean) were omitted from further analysis.

\section{RESULTS}

\section{Irish Case/Control Discovery Data Set}

After all QC, the data set consisted of 706 probands and affected siblings, $464(65.7 \%)$ male and $242(34.3 \%)$ female, mean age 41.8 (SD 9.8) years, and 1,748 population controls, $755(43.2 \%)$ male and $993(56.8 \%)$ female, mean age 37.2 (SD 12.6) years, with $8,344,348$ SNPs for analysis. The Manhattan plot for case/control analysis of $\mathrm{AD}$ is shown in Fig. 1. The QQ plot for the final data set after imputation and all QC is shown in Fig. 2.

\section{Variation in COL6A3 is Associated with AD}

In single marker analyses, 14 SNPs defining 2 independent genomic intervals achieve genomewide significance, 13 within the collagen VI A3 (COL6A3) gene on chromosome 2q37.2 (Fig. 3A), including the most significant SNP in our study, rs2256485, $p=6.17 \times 10^{-9}$ (Table 1). COL6A3 encodes an extracellular matrix (ECM) protein expressed in brain. Although there is no prior human association evidence for this gene, remodeling of the ECM has been strongly implicated in response to various drugs of abuse (Lubbers et al., 2014). The second interval is defined by a single SNP (rs150268941, $p=1.65 \times 10^{-8}$, Table 1) on chromosome 3q26.31 (Fig. S5A). 


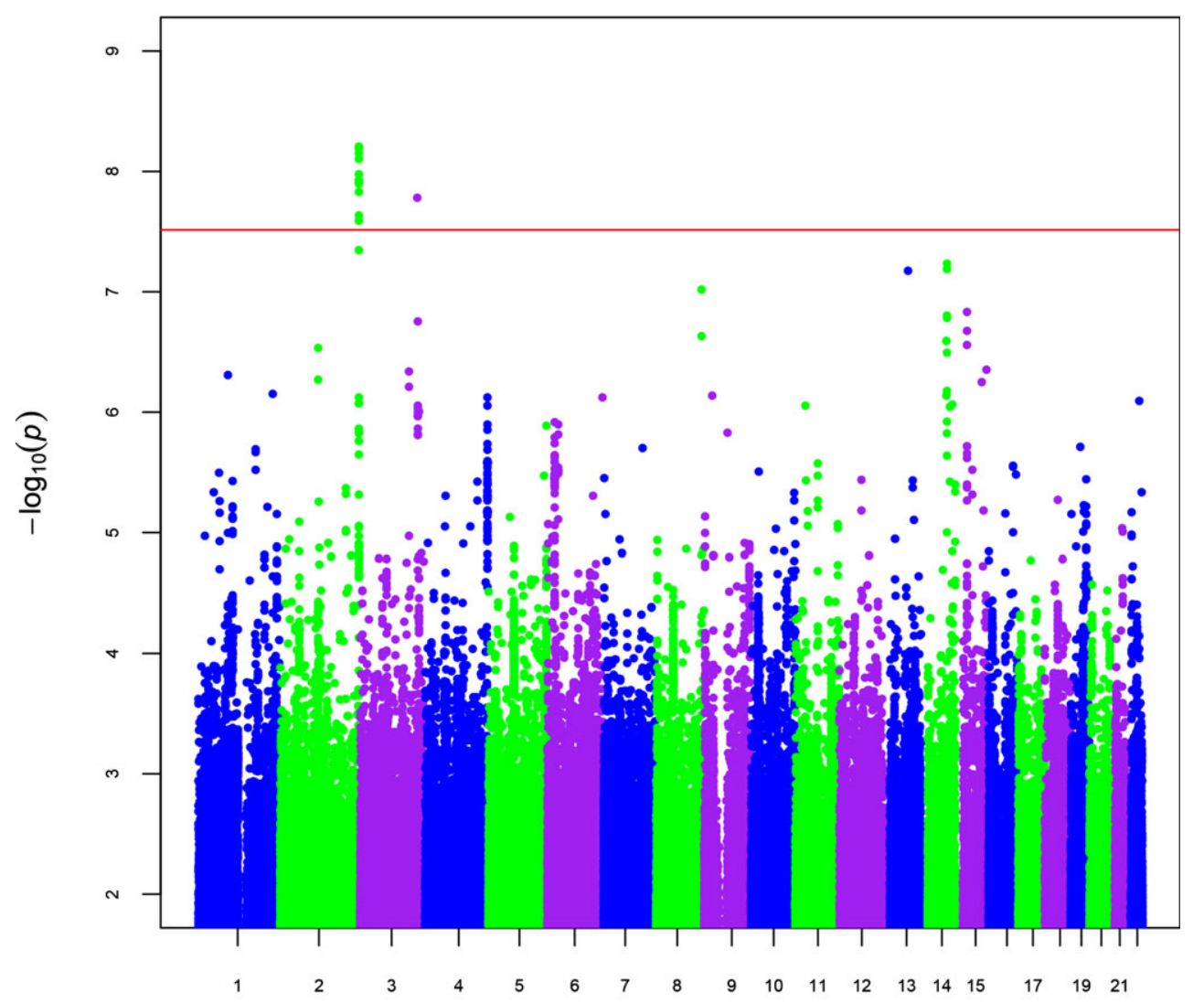

\section{Chromosome}

Fig. 1. Manhattan plot for case/control analysis of alcohol dependence. Horizontal red line indicates genomewide significance $\left(5 \times 10^{-8}\right)$.

\section{Additional Loci are Suggestively Associated with AD}

A total of 28 SNPs in 7 LD-independent loci had $q<0.1$ (Table 1). These include SNPs in 2 loci with prior support from both human and MO alcohol studies (the ryanodine receptor $3[R Y R 3]$ gene, chr. $15 \mathrm{q} 14, \mathrm{rs} 4780153, p=1.47 \times$ $10^{-7}$, Fig. $3 B$, and the Krueppel-like factor 12 [KLF12] gene, chr. 13q22.1, rs117695261, $p=6.63 \times 10^{-8}$, Fig. 3C). Four additional regions with suggestive signals are shown in Fig. S5B-E.

If the Fisher's combined probability test from GWAS3D provided increased evidence based on potential function of the test SNP or a SNP in LD with the test SNP, the combined $p$-value is also shown in Table 1. Of the 28 SNPs with $q<0.1$ input to GWAS3D, 14 showed more significant combined $p$-values after incorporating evidence of function. Of these 14 results, 12 were based on evidence of functional impact for the GWAS target SNP itself. For the 2 sites where the increased evidence was based on putative functional impact of a variant in LD with the GWAS signal, the LD SNP rsID, $r^{2}$ with the GWAS target and functional evidence are shown. GWAS3D analysis yields strongly enhanced signals in COL6A3 (rs2646265: $p=1.47 \times 10^{-8}$, combined $p$ $=1.40 \times 10^{-12} ;$ rs $2256485: r^{2}=1$ with $\operatorname{rs} 2646265, p=6.17$ $\times 10^{-9}$, combined $\left.p=6.18 \times 10^{-13}\right)$ and RYR3 (rs4780153: $r^{2}=0.867$ with $\mathrm{rs} 2076954, p=1.47 \times 10^{-7}$, combined $p=$ $\left.7.92 \times 10^{-10}\right)$.

The signals at 3q26.31 (Fig. S5A) and KLF12 (Fig. 3C) are with single imputed SNPs of low minor allele frequency (MAF). In 1000 Genomes Phase 3 data from U.K. subjects (GBR, British residents of England and Scotland), rs117695261 (MAF 0.03) in KLF12 has no $r^{2}>0.2$ with any other SNP, consistent with the lack of correlated signals in Irish subjects. By contrast, rs150268941 on 3q26.31 is tagged by rs148750402, which was imputed and analyzed in our sample $(0.034, p=0.00147, q=0.754464)$. Direct genotyping of rs150268941 also did not support the observed association (see Appendix S1), and we did not consider the chromosome 3q26.1 region further.

\section{Human Replication}

A total of 274 SNPs had discovery $q<0.3$, and were included in replication. SNAP analysis indicated that 121 represent LD-independent tests, setting replication significance at $0.05 / 121=0.0004$. Lookup replication and metaanalysis results arranged by chromosome and base pair are also shown for all 28 SNPs with $q<0.1$ in Table 1 . Table S1 shows these results for all 274 SNPs with $q<0.3$. No 


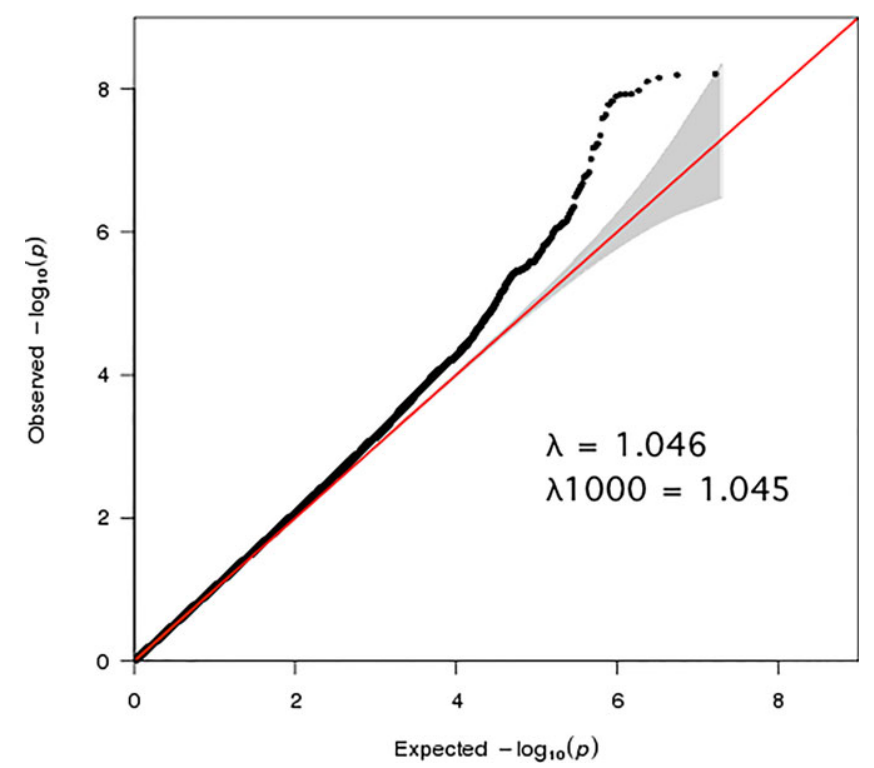

Fig. 2. $Q Q$ plot for final postimputation data set after all quality control and exclusions. Gray shading indicates 95\% confidence interval for expected values. The postimputation lambda (1.046) and sample sizestandardized lambda1000 (1.045) indicate there is little inflation of test statistics.
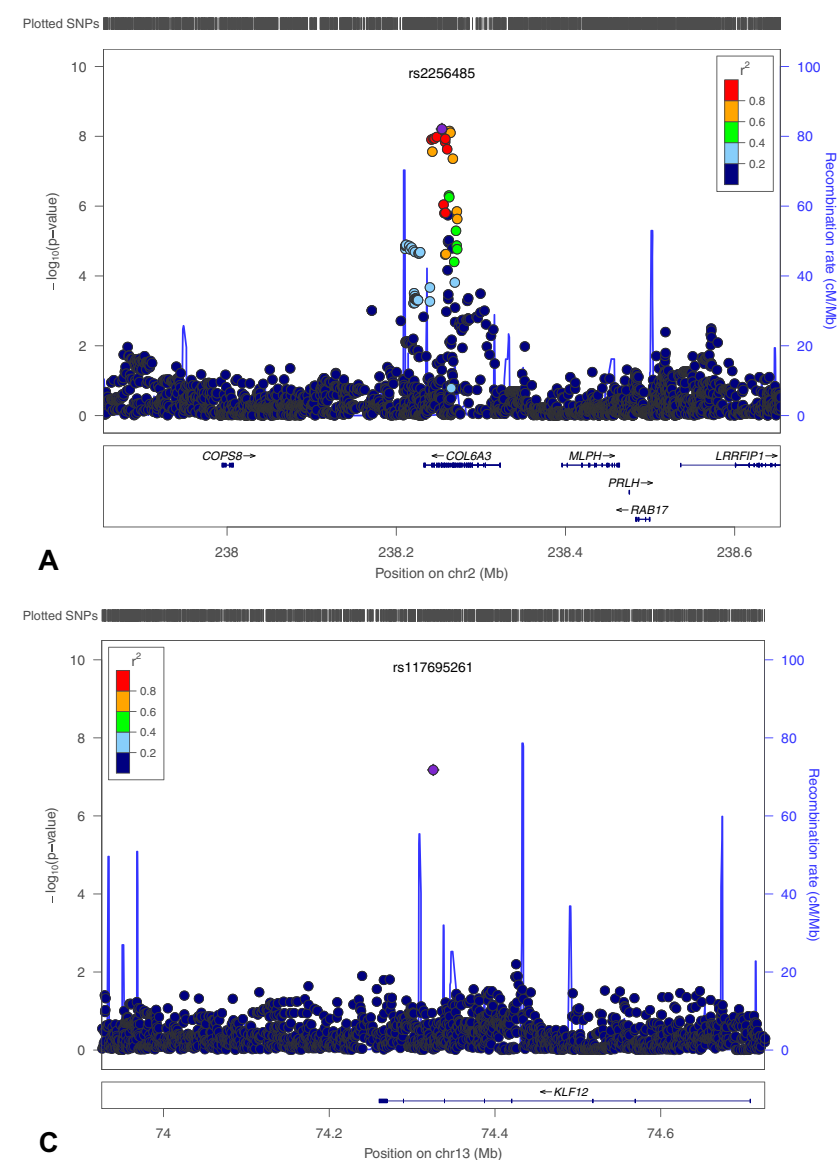

individual SNP achieved $p<0.0004$ in any sample. In metaanalysis of the 4 case-control samples, 1 SNP in a second novel locus, the long noncoding RNA (lncRNA) gene LOC339975 showed a GWS signal (chr. 4q35.2, rs11726136, $p=7.52 \times 10^{-7}, q=0.149$ in the discovery sample, Fig. $3 D$, and GWS $p=4.20 \times 10^{-8}$ in meta-analysis of the 4 case/ control samples, Table 1 and Table S1). Because of differences in ascertainment and severity of affection, we performed replication analyses including the Australian population sample separately; this signal was not significant when the Australian sample was included (Table S1).

We also assessed evidence in our discovery data for association with loci identified in prior AD GWAS in subjects of European ancestry. We detect modest signals in PECR (minimum $p=0.0017$ ), AUTS2 (minimum $p=0.0009$ ), and ADH1B (minimum $p=0.00166$ ), but none of these signals are with the SNPs originally reported (Table S2). We detect no evidence of signal in c15orf53 (minimum $p=0.2058$ ).

\section{Secondary Analyses}

Results of secondary analyses of discovery GWAS data are shown in Table S3 (gene-based analyses), Fig. S6 and
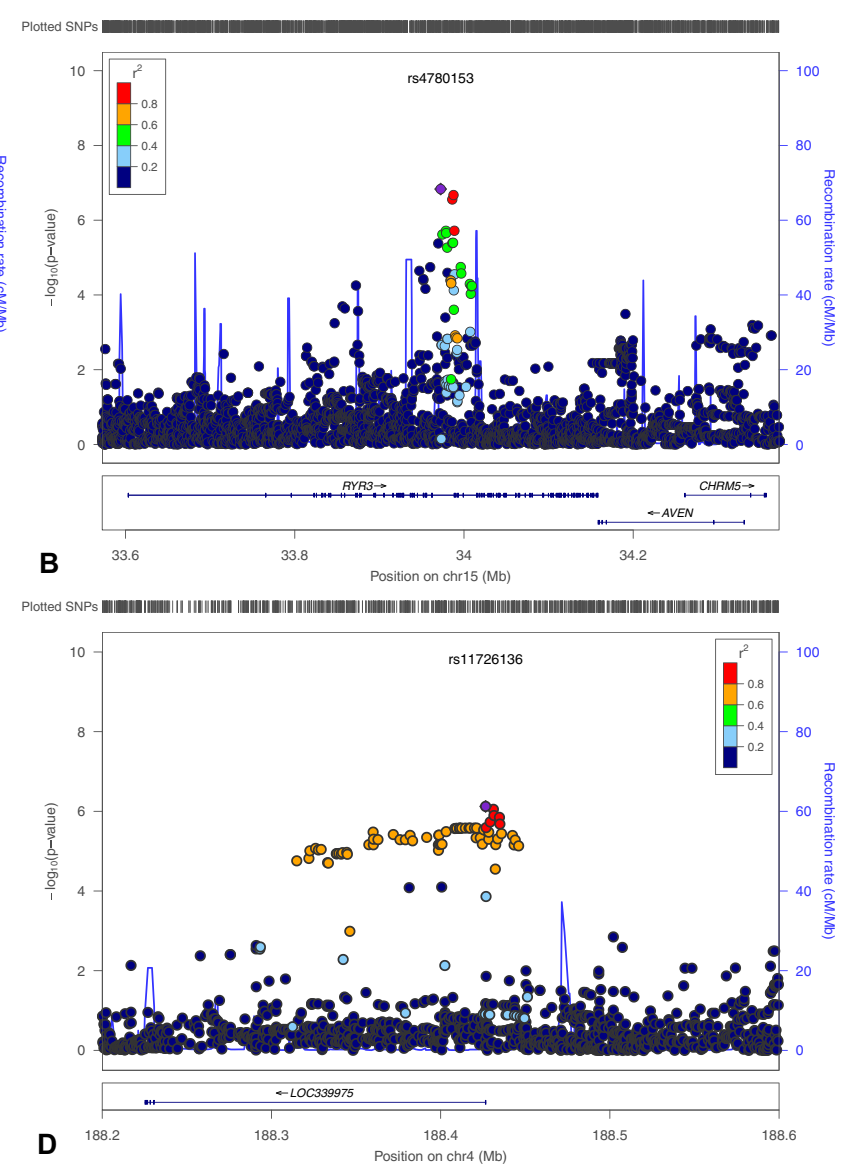

Fig. 3. LocusZoom plots of COL6A3, RYR3, KLF12 and LOC339975. Genomewide significant results in COL6A3 (A) and 3 other regions of suggestive association supported by additional data, RYR3 (B), KLF12 (C), and LOC339975(D). 


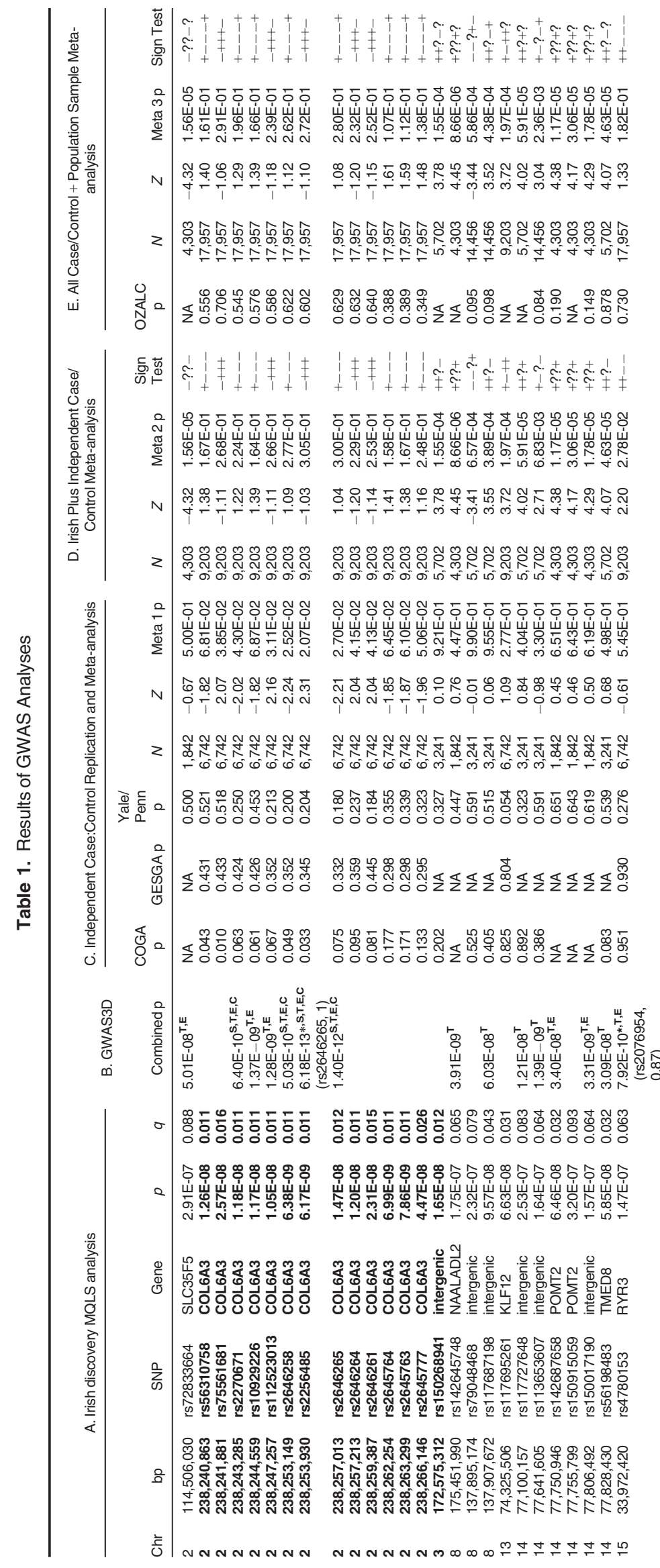

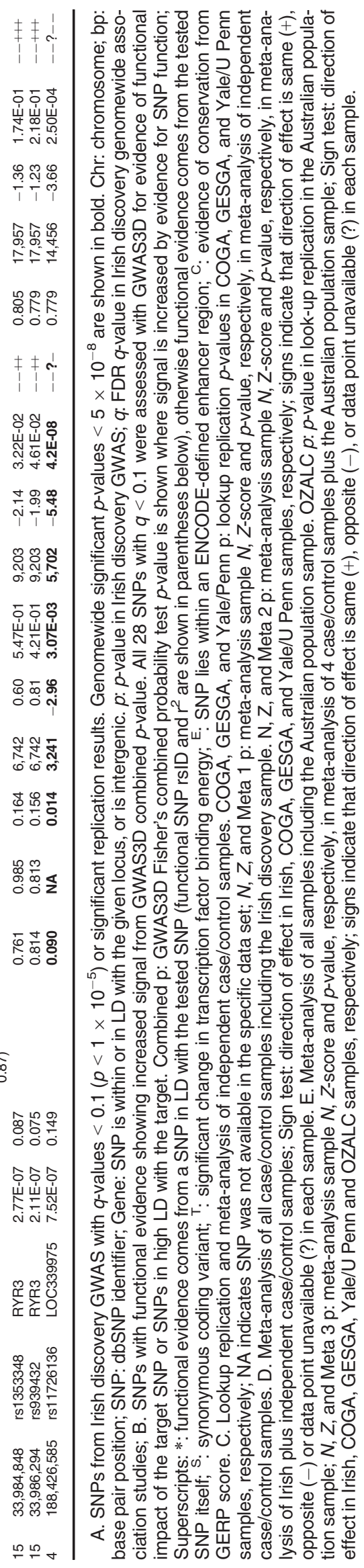


Table S4 (network analyses) and Table S5 (geneset analyses). Gene-based analyses assess over representation of case-control allele frequency differences in all SNPs within defined genic regions (with LD pruning or weighting as described in Supplementary Materials and Methods in Appendix S1). The hybrid set-based test incorporated in Knowledge-Based Mining System for Genome-Wide Genetic Studies (KGG) shows strong gene-based association of $\mathrm{AD}$ with COL6A3 $\left(p=7.30 \times 10^{-9}, q=0.00016\right), R Y R 3\left(p=2.62 \times 10^{-7}\right.$, $q=0.0029)$, and LOC339975 $\left(p=5.31 \times 10^{-6}, q=0.0248\right)$ (Table S3).

\section{Selection for Functional Studies}

We undertook functional studies of 4 candidate loci, COL6A3, and LOC339975 based on the GWS signals in discovery or replication analyses and KLF12 and $R Y R 3$ based on discovery $q<0.1$ and prior evidence of implicating these loci in alcohol-related phenotypes (reviewed below). We used established behavioral paradigms to test orthologs of COL6A3, KLF12, and RYR3 for effects on behavioral responses to EtOH in C. elegans and Drosophila where orthologous genes were present in the models and genetic reagents and information were available. We analyzed correlation between brain gene expression and alcohol-related phenotypes in BXD mouse data for all 3 genes. All these studies are summarized in Table 2, and we report here the results of all studies performed. We additionally tested the effect of the ryanodine receptor antagonist dantrolene on $\mathrm{EtOH}$ self-administration in rats. The fourth gene, LOC 339975, is primate-specific and was taken forward for study in human postmortem brain.

COL6A3: Regulation of EtOH Sensitivity in C. elegans and Correlation with Handling-Induced Convulsions in Mice

We tested 3 C. elegans genes with equally high orthology to human COL6A3 for effects on initial sensitivity and AFT. RNAi knockdown of C16E9.1 decreased initial sensitivity compared to control RNAi animals $(p<0.05$, Fig. $4 A$ ) but did not affect the development of AFT. RNAi knockdown of the other COL6A3 orthologs (C18H7.1 and cutl-23) produced no significant differences in either measure (Fig. 4B,C). Statistics and uncorrected basal speed data for all $C$. elegans experiments are shown in Table S6.

In mice, Col6a3 is located within the Alcw5 QTL interval (MGI:3037048) for handling-induced convulsions (HIC) following 72-hour EtOH vapor exposure (Bergeson et al., 2003). The Alcw5 QTL maps to 39.16 centiMorgans (cM) on mouse chromosome 1, with a support interval of 28 to $47 \mathrm{cM}$. After converting $\mathrm{cM}$ to megabase pairs $(\mathrm{Mb})$ for the latest version of the mouse genome (GRCm38/mm10), this yields a physical location of the Alcw5 QTL peak of $75.57 \mathrm{Mb}$ and a QTL support interval of 62.12 to
107.66 Mb. Col6a3 is located at mouse chr1:9076686090843971, within the defined Alcw5 QTL support interval.

In GeneNetwork, the strongest correlation observed for mouse Col6a 3 basal whole brain expression (GN113, probeset 1424131_at_A) is with total HIC score (sum of baseline subtracted HIC at 4, 6, and 7 hours) after $4 \mathrm{~g} / \mathrm{kg} \mathrm{IP} \mathrm{EtOH} \mathrm{in}$ males (Philip et al., 2010) (trait 11,382, correlation rank $=1$, rho $=0.959, p=1.05 \times 10^{-9}, N=13$ strains, Fig. $5 A$ ), which surpasses our Bonferroni-corrected significance level of $p=2.5 \times 10^{-5}$. HIC at 7 hours in males (trait 11,380, correlation rank $=2$, rho $=0.835, p=3.11 \times 10^{-6}, N=18$ strains) and in males and females (trait 11,894, correlation rank $=3$, rho $=0.780, p=5.11 \times 10^{-5}, \quad N=18$ strains) (Philip et al., 2010) are also strongly correlated with Col6a3 expression, and all 3 HIC measures are highly correlated (phenotypic rho $=0.91$ to 0.95 ). Col6a3 expression correlated negatively with 2-bottle choice EtOH preference (Phillips et al., 1994) (trait 10,479, correlation rank $=67$, rho $=-0.569, p=0.0124, N=18$ strains, Fig. $5 B$ ). While this is not significant after multiple test correction, it is consistent with the expectation that factors increasing HIC will decrease voluntary consumption (Metten et al., 1998).

\section{KLF12: Regulation of AFT to EtOH in C. elegans and Gene Expression Correlation with Locomotor Activity in Mice}

There is significant prior evidence for a role of KLF12 in EtOH-response behaviors across species. In BXD mice, Klf12 is regulated by acute EtOH in PFC, NAc, and VTA, and is a hub in a network of EtOH-responsive genes (Wolen et al., 2012). In humans, KLF12 acts in combination with the co-repressor CTBP1 (Schuierer et al., 2001), and in C. elegans, the $c t b p-1$ gene is required for the development of AFT (Bettinger et al., 2012). The closest $C$. elegans ortholog to human $K L F 12$ is $k l f-3$, and this evidence collectively suggests KLF-3 is likely to act together with CTBP-1 to regulate AFT in worms.

We tested a strong loss-of-function allele in $k l f-3$. There was no difference in initial sensitivity between wild-type N2 and klf-3(ok1975) mutants (Fig. 4D). While wild-type N2 animals demonstrated normal AFT at 30 minutes, klf-3 mutants failed to develop AFT (Fig. $4 D, t$-test of degree of speed recovery between 10 and 30 minutes, $400 \mathrm{mM}$ EtOH: $\mathrm{N} 2$ versus $\left.k l f-3(o k 1975), t_{3}=8.99, p<0.001\right)$. These data strongly suggest that the transcriptional regulation provided by KLF-3 is required for the development of AFT in worms.

Based on patterns of regulation of mouse Klf12 by EtOH (Wolen et al., 2012), we analyzed correlation between basal Klf12 expression in mouse PFC (GN135), NAc (GN156), VTA (GN228), and whole brain (GN113) data sets and BXD panel phenotypes in GeneNetwork. The strongest correlations observed for basal Klf12 expression in PFC (GN135, probeset 1455521_at) were with locomotor activity 0 to 5 minutes (trait 11,708 , correlation rank $=1$, rho $=0.756, p=1.69 \times 10^{-5}, N=22$ strains, Fig. $\left.5 C\right)$ and 0 to 20 minutes (trait 11,705 , correlation rank $=3$, 


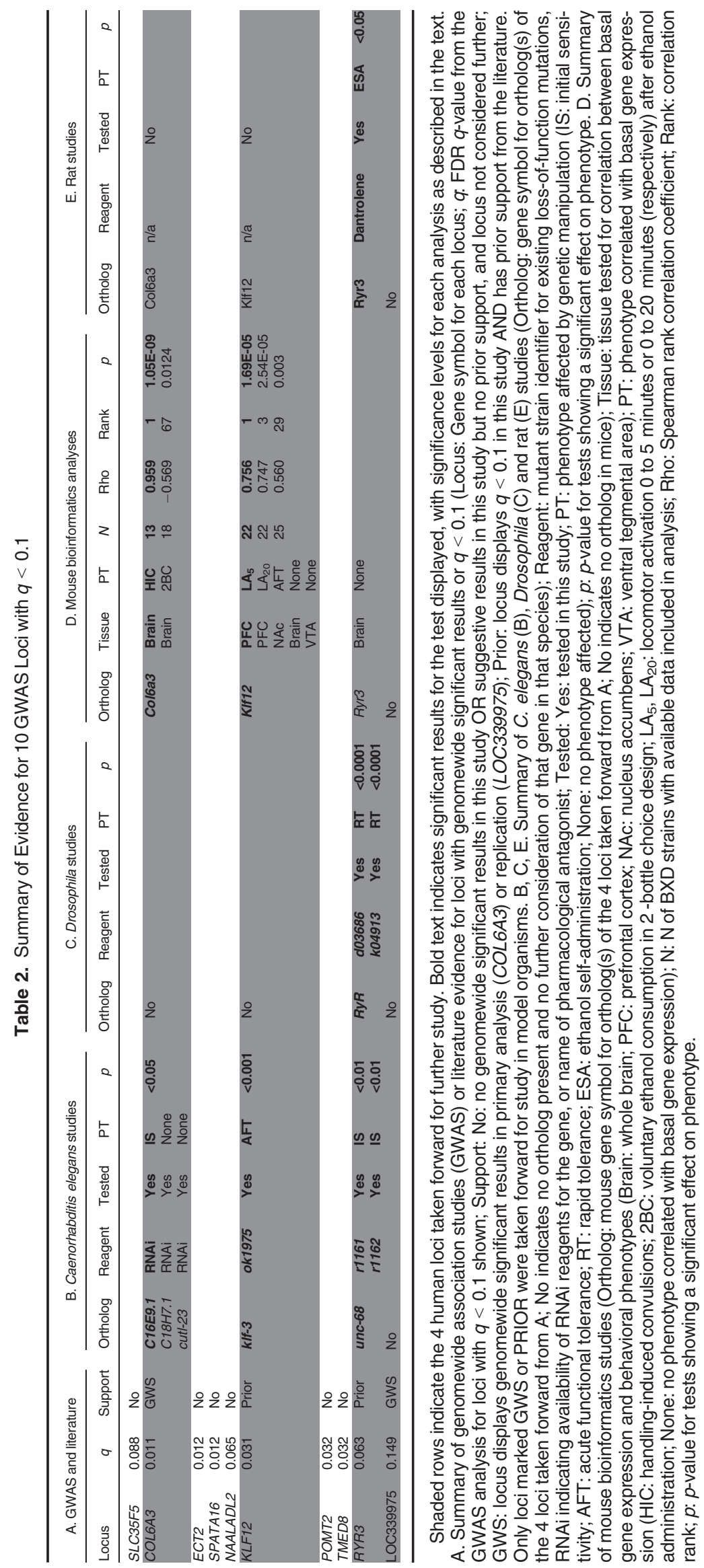



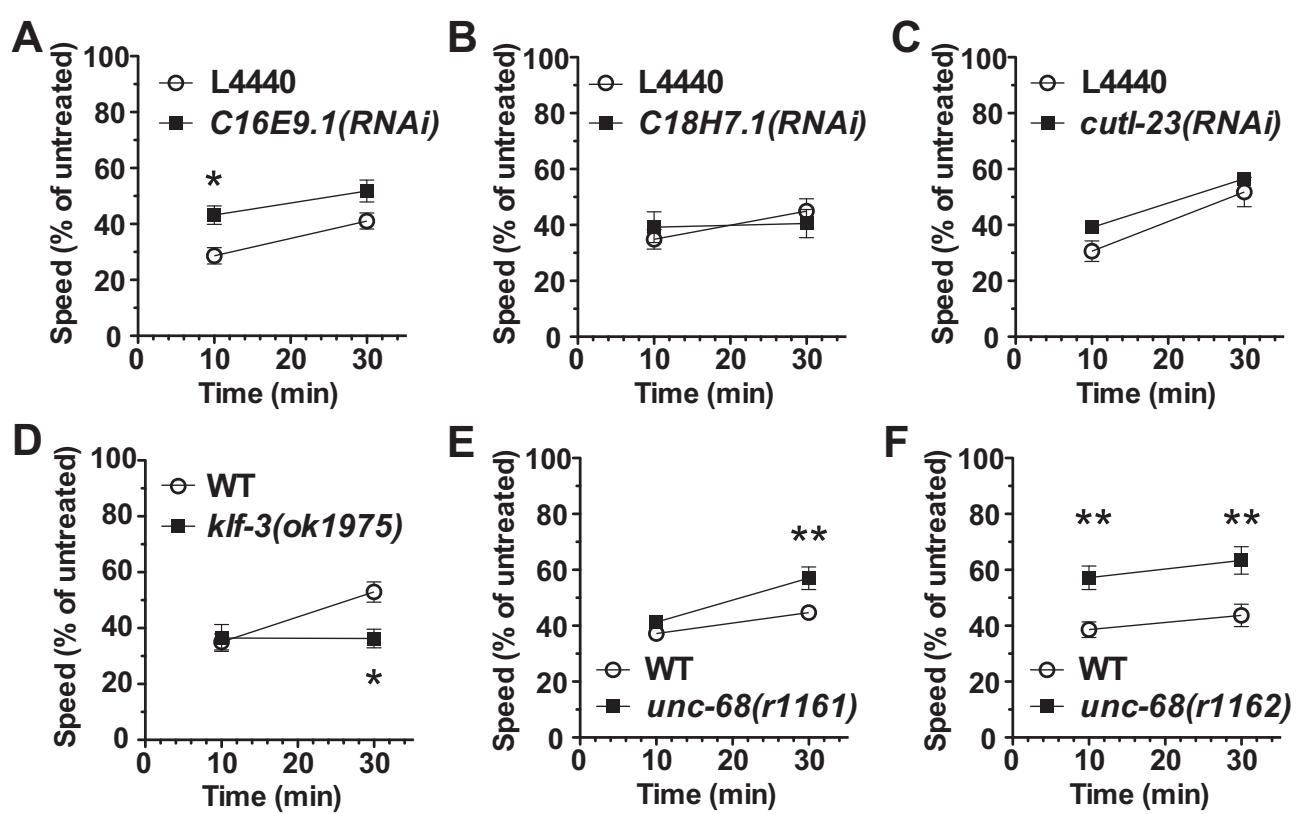

Fig. 4. Mutations in Caenorhabditis elegans orthologs of human candidate genes cause ethanol (EtOH)-response phenotypes. Speed of locomotion was measured at 10 and 30 minutes, and expressed as a percent of the untreated control speed. Control worms were tested simultaneously on the same plates. Worms were treated with $400 \mathrm{mM}$ exogenous EtOH. The waxy cuticle of worms excludes most of the exogenous EtOH; tissue concentrations are approximately $12 \%$ of the exogenous dose $(-48 \mathrm{mM})$. (A, B, C) RNAi-induced gene knockdown reduced sensitivity to EtOH for C16E9.1 (a COL6A3 ortholog) but not for 2 other orthologous genes relative to untreated worms. (D) Loss of function of the KLF12 ortholog, klf-3, prevented the development of acute functional tolerance between the 10- and 30-minute time points relative to wild-type N2. (E, F) unc-68 mutant animals demonstrate reduced sensitivity to EtOH relative to wild-type N2. Statistical significance is shown for 2-way ANOVA followed by post hoc comparisons across genotypes $(* p<0.05, * * p<0.01)$.

rho $=0.747, p=2.54 \times 10^{-5}, N=22$ strains) after $2.25 \mathrm{~g} /$ $\mathrm{kg}$ IP EtOH in females (Philip et al., 2010). The first result remains significant, and the second falls just below significance after Bonferroni correction. Basal Klf12 expression in mouse NAc (GN156, probeset 1439847_s_at) was positively correlated with AFT (Kirstein et al., 2002) (trait 10,348, correlation $\mathrm{rank}=29$, rho $=0.560, p=0.003, N=25$ strains, Fig. 5D). While not significant after Bonferroni correction, this is consistent with the failure to develop AFT in C. elegans klf-3 mutants.

\section{RYR3: Regulation of Initial Sensitivity to EtOH in} C. elegans, Rapid Tolerance to EtOH in Drosophila, and Motivation to Self-Administer Alcohol in Rats

Previous studies have implicated ryanodine receptors (RyR) in EtOH phenotypes: In humans, RYR3 was implicated in a GWAS of alcohol response (Joslyn et al., 2010). Ryr1 and Ryr2 up-regulation in mouse brain is observed following acute exposure to multiple drugs including alcohol (Kurokawa et al., 2010, 2013) and behavioral changes like conditioned place preference and withdrawal expected following acute exposure are blocked by the RyR antagonist dantrolene (Kurokawa et al., 2010, 2013).

C. elegans has 1 RyR gene, unc-68. We tested the effect of EtOH on 2 strains carrying different $u n c-68$ mutations ( $r 1161$ and r1162). Loss of unc-68 confers reduced sensitivity to EtOH (minimum $p<0.001$ for $r 1162$, Fig. $4 E, F$ ). We also observed consistent effects of mutations in 2 additional genes with products involved in calcium regulation and known to interact with UNC-68 (Supplementary Materials and Methods, Supplementary Results, and Fig. S7 in Appendix S1).

There is a single RYR3 ortholog in Drosophila, $R y R$. We found that 2 insertional mutations that cause partial loss of function in $R y R$ reduce the development of rapid tolerance to EtOH with no obvious effects on initial sensitivity (Supplementary Materials and Methods, Supplementary Results and Fig. S8 in Appendix S1).

The mouse Ryr3 gene is localized to the support intervals for a complex group of EtOH behavioral QTL mapped to Chr 2 but Ryr3 basal whole brain expression (GN113; probeset 1427427_at) is not strongly correlated with EtOH-related phenotypes.

The availability of dantrolene, a pharmacological antagonist of ryanodine receptors, allowed us to assess the effect of antagonism of RyRs on the complex behavior of EtOH self-administration in rats. We found that in rats, dantrolene dose dependently reduced motivation to self-administer EtOH after 50 contiguous days of chronic EtOH self-administration (Supplementary Materials and Methods, Supplementary Results, and Fig. S9 in Appendix S1).

\section{rs11726136 Genotype Alters LOC339975 Expression in Human NAC}

LOC339975 shows homology only with sequences from other primates. To assess the potential functional impact of 
A

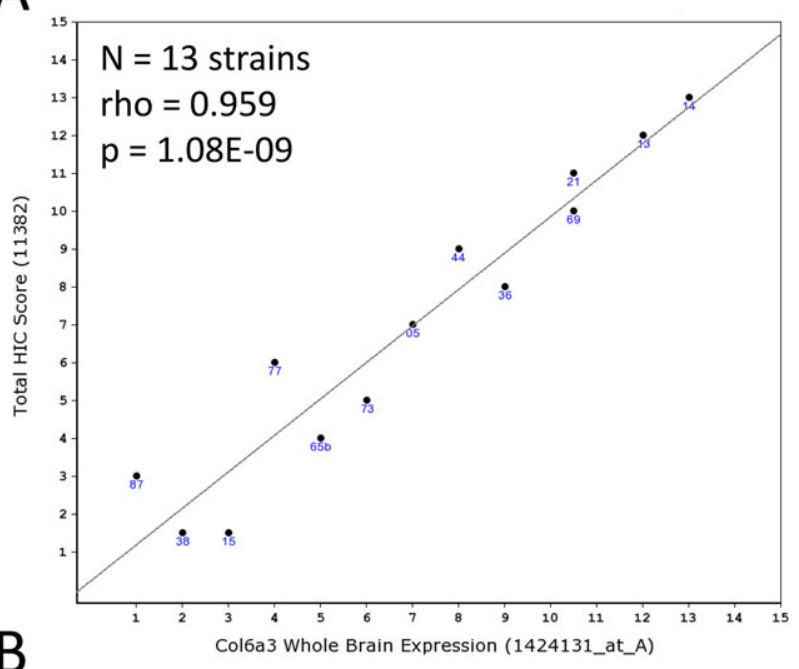

B

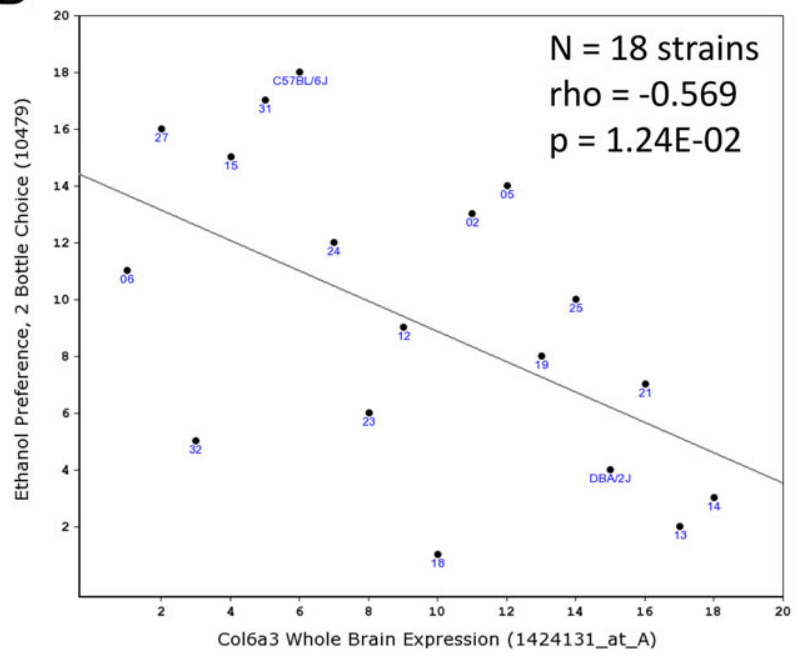

C

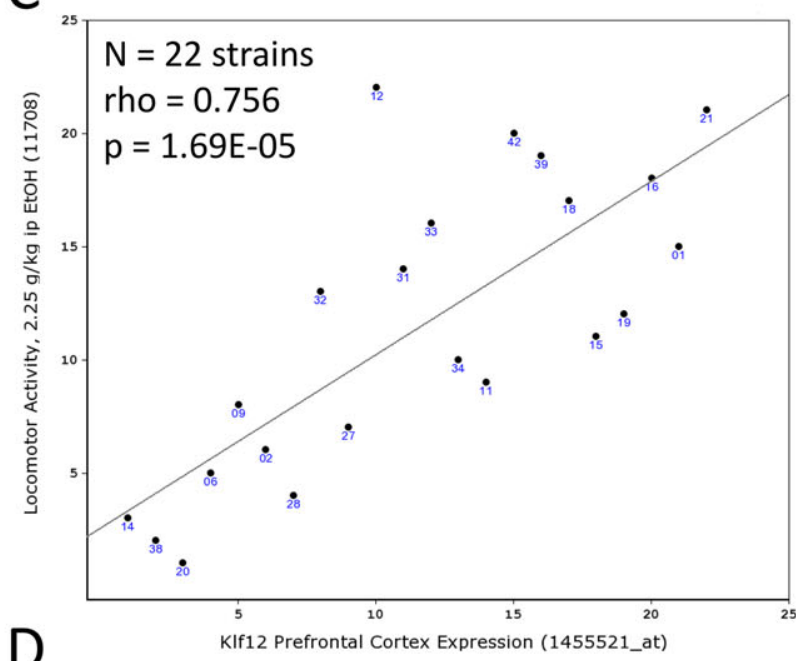

D

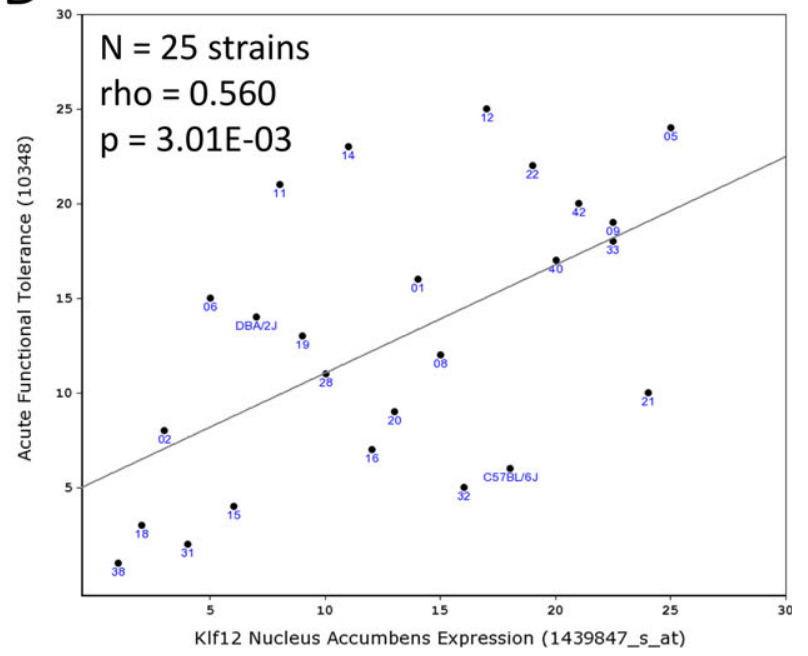

Fig. 5. Bioinformatic analysis of correlation of Col6a3, KIf12, or Ryr3 expression with ethanol (EtOH) behaviors in C57BL/6J x DBA/2J recombinant inbred (BXD) mouse lines. The GeneNetwork (GN) web-based analysis platform was used to identify correlations between basal expression levels of Col6a3, Klf12, or Ryr3 and EtOH behaviors. Panels A-D display Spearman ranked order correlations between microarray gene expression ( $x$-axis) and behavioral phenotypes ( $y$-axis). Col6a3 (probeset 1424131_at) in GN113 whole brain expression data set showed significant positive correlation with total handling-induced convulsion (HIC) score (sum of baseline subtracted HIC at 4, 6 and 7 hours) after $4 \mathrm{~g} / \mathrm{kg}$ intraperitoneal (IP) EtOH in males (GN record 11382; Panel A) and negative correlation with EtOH 2-bottle choice voluntary consumption (GN record 10479; Panel B). KIf12 basal expression in prefrontal cortex (GN135, probeset 1455521_at) was significantly positively correlated with locomotor activity 0 to 5 minutes after $2.25 \mathrm{~g} / \mathrm{kg}$ IP EtOH (GN record 11708; Panel C) and in nucleus accumbens (GN156, probeset 1439827_s_at) was positively correlated with EtOH acute functional tolerance (GN record 10348; Panel D).

alleles at rs11726136, we therefore tested AD case and control postmortem tissue from PFC and NAc for differences in LOC339975 expression by clinical status or genotype. The final numbers available for analysis were for PFC, 28 cases and 30 controls and 50 reference allele $\mathrm{T} / \mathrm{T}$ and $5 \mathrm{~T} / \mathrm{G}$ genotypes, and for NAc, 34 cases and 35 controls and $58 \mathrm{~T} / \mathrm{T}$ and $7 \mathrm{~T} / \mathrm{G}$ genotypes (Table S7).

We included age, sex, ethnicity, brain weight, brain $\mathrm{pH}$, PMI, tissue hemisphere, cause of death, blood toxicology, smoking status, neuropathology, and liver pathology as covariates in analysis. Neuropathology and brain weight were both significantly associated with expression level in the NAc; no covariates were associated with expression level in the PFC (Table S7). We detected no difference in expression level between AD cases and controls in either NAc $(p=0.75)$ or PFC $(p=0.23)$ (Fig. $6 A, B$ and Table S7 $A, B)$. After controlling for covariates, expression of LOC339975 is significantly reduced in carriers of the associated nonreference allele in NAc $(p=0.003$, Fig. $6 C$, Table S7C) but did not differ by genotype in PFC $(p=0.54$, Fig. $6 D$, Table $\mathrm{S} 7 D$ ). Alternative regulation in NAc and PFC is consistent with the presence of several distinct transcription factor binding sites upstream of lncRNA genes (Alam et al., 2014). Although we do not detect case/control differences in expression, our data suggest the associated allele of rs11726136 has functional consequence based on the reduced 
A

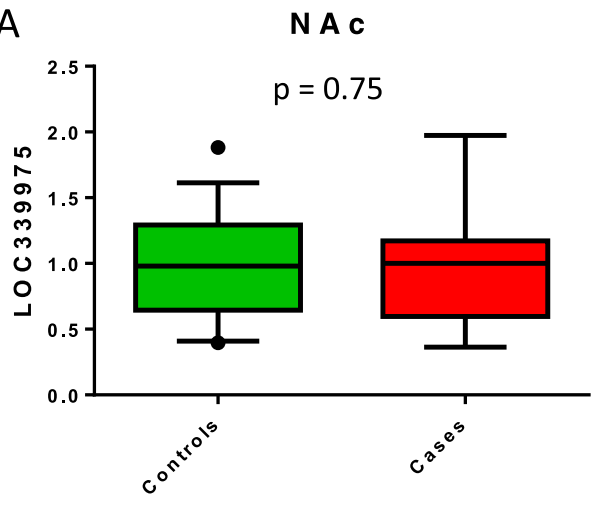

C

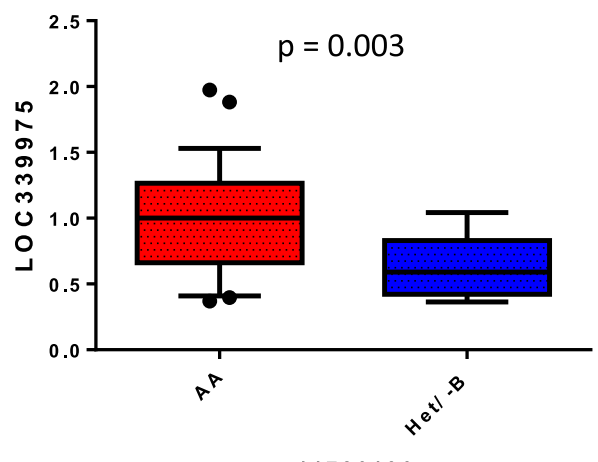

B

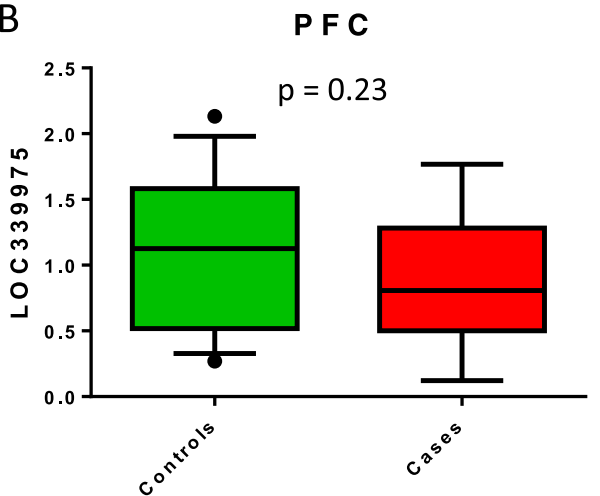

D

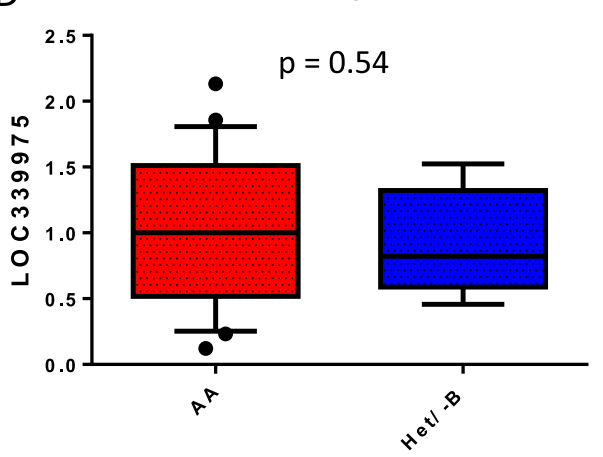

rs 11726136

Fig. 6. Expression of long noncoding RNA LOC339975 in human postmortem nucleus accumbens (NAc) and dorsolateral prefrontal cortex (PFC) stratified by diagnostic status and by genotype. Control mean RIN was $5.6(\mathrm{SD}=1.8)$, case mean RIN was $5.8(\mathrm{SD}=1.5)$, and did not differ between cases and controls (Mann-Whitney $p=0.78$ ). Samples that did not amplify (NAc, $N=13$; PFC, $N=24$ ) and 4 samples missing rs11726136 genotypes were excluded. Case:control comparisons of LOC339975 expression in (A) 34 case and 35 control NAc samples, and (B) 28 case and 30 control PFC samples. There were no significant differences in expression between diagnostic groups. Genotypic comparisons of LOC 339975 expression in (C) 58 reference (T/T) homozygote and $7 \mathrm{~T} / \mathrm{G}$ heterozygote NAc samples, and (D) $50 \mathrm{~T} / \mathrm{T}$ homozygote and $5 \mathrm{~T} / \mathrm{G}$ heterozygote PFC samples. While no significant differences in expression by genotype were observed in the PFC, NAc expression was significantly reduced in carriers of the associated nonreference $G$ allele compared to reference allele homozygotes $(F=9.72, p=0.003)$.

LOC339975 expression observed in the NAc in heterozygotes.

\section{DISCUSSION}

We identified 2 novel GWS association signals in COL6A3 and LOC339975, and suggestive signals in a number of loci, including 2 genes with prior support, KLF12 and RYR3. COL6A3, RYR3, and LOC339975 are further supported by gene-based analyses (Table S3). We detect evidence of human replication only for LOC339975 but we observe consistent evidence across multiple MOs that COL6A3, KLF12, and RYR3 orthologs modulate behavioral response to EtOH. Human postmortem studies show that the AD-associated allele reduces LOC339975 expression in NAc.

\section{Collagen VI A3 (COL6A3)}

Collagen IV (Joslyn et al., 2010) and VIII (Edenberg et al., 2010) genes were implicated in EtOH response and
AD. COL6A3 is located in a QTL interval for alcohol withdrawal identified in the IASPSAD sample (Kuo et al., 2006). Although this signal did not replicate, our GWS association with potentially functional SNPs (GWAS3D results, Table 1) is supported by the reduced sensitivity after RNAi knockdown in C. elegans (Fig. $4 A$ ), mapping to the Alcw5 QTL for HIC in mice and the strong correlation between expression and HIC in BXD lines (Fig. 5A). COL6A3 encodes a component of the ECM, and there is mounting evidence (Lubbers et al., 2014) that multiple substances of abuse increase ECM remodeling and that remodeling is required for the expected behavioral changes following exposure. EtOH dose dependently induces tissue plasminogen activator (tPA), required for ECM remodeling, which enhances EtOH reward (Bahi and Dreyer, 2012). Withdrawal seizures are reduced in tPA-deficient mice following chronic EtOH administration (Pawlak et al., 2005). Inhibition of proteolytic enzymes that degrade the ECM block escalated responding during acute withdrawal in dependent animals (Smith et al., 2011). Collectively, these results argue that ECM structural components (like COL6A3) and 
remodeling enzymes are important determinants of EtOHinduced neuroadaptation. We hypothesize that Col6a3 may underlie the Alcw5 HIC QTL.

\section{Krueppel-Like Factor 12 (KLF12)}

Klf12 is regulated by acute $\mathrm{EtOH}$ in mouse brain and is a hub in a network of EtOH-responsive genes (Wolen et al., 2012) including many implicated in EtOH response (e.g., Grm3 (Gass and Olive, 2008), Kcnmal (Davies et al., 2003), and Gsk3b (French and Heberlein, 2009)). Orthologs of KLF12 (Fig. 4D) and its binding partner CTBP1 (Bettinger et al., 2012) are required for the development of AFT in C. elegans. The targets of KLF12 regulation are not yet known, but the convergent evidence argues strongly they are central to acute EtOH response and potentially relevant to AD risk.

\section{Ryanodine Receptor 3 ( $R Y R 3$ )}

$R Y R 3$ was implicated in a GWAS of EtOH response (Joslyn et al., 2010) and our observed association may be driven by functional SNPs (GWAS3D analysis, Table 1). In $C$. elegans, loss of the single RyR gene unc-68 reduces initial sensitivity to $\mathrm{EtOH}$ (Fig. $4 E, F$ ). This mutation would be predicted to decrease intracellular $\mathrm{Ca}^{2+}$. Consistent with this observation, we found that mutations in $\operatorname{csq}$ 1 , which would be predicted to increase intracellular $\mathrm{Ca}^{2+}$ concentration, increase initial sensitivity (Fig. S7A). Mutations in the ether-a-go-go-related potassium channel gene unc-103, which has a genetic interaction with unc-68, also decrease sensitivity to EtOH (Fig. S7D). In Drosophila, reduction in function of the $R y R$ gene blunts rapid tolerance (Fig. S $8 B$ ).

The RyR antagonist dantrolene reduces cocaine (Kurokawa et al., 2011) and methamphetamine (Kurokawa et al., 2010) induced conditioned place preference, EtOH withdrawal symptoms (Kurokawa et al., 2013), and motivation to self-administer $\mathrm{EtOH}$ after chronic exposure in a dose-dependent manner in rats (Fig. S9), but these studies are limited by the nonspecificity of dantrolene, an antagonist of both ryanodine and inositol triphosphate receptors, the latter functioning upstream of RyR activation. In myocytes, RyRs provide the $\mathrm{Ca}^{2+}$ ions that activate BK channels (Lifshitz et al., 2011), which have strong effects on EtOH response in vivo and in vitro (Davies et al., 2003; Martin et al., 2008). EtOH modulates BK channel function in a calcium-dependent manner (Liu et al., 2008), and we hypothesize that RyRs may be involved in this calcium-dependent modulation of BK channel function.

\section{$\operatorname{lncRNA}$ LOC339975}

lncRNA are of emerging importance in the function and dysfunction of the brain (Roberts et al., 2014). Expression of the estimated 25 to $50 \mathrm{~K}$ lncRNA genes in the human genome (Hangauer et al., 2013) is widespread in the brain and highly regulated (Guttman et al., 2011; Mercer et al., 2008). lncRNA are implicated in multiple neurodevelopmental, neurodegenerative, and neuropsychiatric diseases, including schizophrenia (Barry et al., 2014), Alzheimer's (Faghihi et al., 2008), autism (Kerin et al., 2012), and neuronal excitability and epilepsy (Barry et al., 2017). A recent GWAS of AD detected GWS association in the lncRNA LOC100507053 (Gelernter et al., 2014). While this signal is part of the larger $A D H$ gene cluster signal reported and associated SNPs could only be analyzed in African Americans due to MAF or imputation information, LOC100507053 is anti-sense to multiple $A D H$ genes, and has potential to regulate their expression. Although the role of these transcripts remains unclear, the growing number of reported associations argues that lncRNA genes are also important in human health and disease. Our data suggest the associated allele of rs11726136 may have functional consequence based on the reduced LOC339975 expression observed in the NAc.

\section{Limitations}

Unscreened controls: While the use of unscreened controls is common in studies of traits with low population prevalence, unscreened controls are not ideal for traits with the high population prevalence of AD (Wellcome Trust Case Control Consortium, 2007). However, the most likely impact of this lack of screening is for a proportion of controls to be unrecognized and phenotypically misclassified cases. This will reduce the contrast between cases and controls, increase type II error and reduce study power to detect effects. Importantly, the use of unscreened controls is not expected to increase type I error and produce spurious positive results.

Lack of strong human replication: The lack of strong human replication is a serious limitation of our study. However, nonreplication of novel signals is common in GWAS of $\mathrm{AD}$ and may have several causes. Specific to our study, differences in sampling, data production, QC, imputation, or analysis can confound meta-analysis. The GESGA sample was imputed to an older, smaller HapMap reference panel, has many missing data points, and shows the least consistent sign tests (Table 1 and Table S1). The OZALC population sample was genotyped at multiple sites, a well-known source of systematic genotype bias. We note that our strongest replication signals come from analyses of the 3 samples (Irish, COGA, and Yale/Penn) with the most consistent ascertainment and genotyping. More generally, this pattern of nonreplication may reflect the multiple independent domains of risk for AD (Kendler et al., 2012), including variation in (i) alcohol-specific physiological measures like initial sensitivity and tolerance (Schuckit et al., 1997), (ii) brain reward circuitry implicated in substance use and other pathological behaviors (Volkow et al., 2012), and (iii) personality traits like internalizing and externalizing behaviors (Harford et al., 
2013), which are unlikely to be influenced by the same genes. As in other complex traits, these issues will be overcome primarily by increasing sample size and power. Finally, as both KLF12 and $R Y R 3$ were previously implicated in substance phenotypes, our findings may be considered as replication evidence for these signals.

Limited phenotypic consilience: Across our MO studies, many different phenotypes are affected by manipulation of candidate orthologs, with little consilience between species. Although mammalian and invertebrate nervous systems show extensive molecular and functional conservation (Bargmann, 1998; Brownlee and Fairweather, 1999) and many drugs mediate their behavioral effects through orthologous target proteins (Kaletta and Hengartner, 2006; Matthews and Kopczynski, 2001), phenotypic consilience and consistent direction of effect following manipulation of a specific gene are not always observed across species (e.g., manipulations of chloride intracellular channel 4 (Clic4) orthologs altered sensitivity in flies and mice but in different directions (Bhandari et al., 2012). There are also differences in EtOHresponse measures available for different MOs (e.g., AFT has not been demonstrated in flies despite direct efforts to elicit this response (Chan et al., 2014)). Within species, we observe consilience across studies for effects of (1) Klf-3 and binding partner Ctbpl on AFT and (2) genes influencing intracellular calcium levels on initial sensitivity in worms, and (3) Col6a3 on HIC in mice.

\section{CONCLUSIONS}

Our combined data implicate COL6A3, KLF12, RYR3, and $L O C 339975$ in response to EtOH across multiple species and/or AD risk in humans. Our data are also consistent with prior work implicating remodeling of the ECM (COL6A3), regulation of EtOH-responsive genes (KLF12), and regulation of intracellular calcium release $(R Y R 3)$ in response to $\mathrm{EtOH}$.

\section{ACKNOWLEDGMENTS (CONSORTIUM ACKNOWLEDGMENTS APPEAR IN APPENDIX S1)}

BPR and KSK thank all the members of the Virginia Commonwealth University Alcohol Research Center for their invaluable insight and helpful discussions. AEA, TBB, LMH, FA, DMD, BSM, SAB, BTW, KSK, and BPR were supported by National Institute on Alcohol Abuse and Alcoholism grants P20 AA017828 to BPR, KSK, MFM, and DMD, R01 AA011408 to KSK and BPR, and R37 AA011408 to KSK. ACE was supported by National Institute on Alcohol Abuse and Alcoholism grant K01 AA021399. Sample collection was supported by previous funding of National Institute on Alcohol Abuse and Alcoholism grant R01 AA011408 to CAP and KSK. Control genotyping was supported by National Institute of Mental Health grant R01 MH083094 to BPR and Wellcome Trust Case Control Consortium 2 grant WTCCC-084710. MG thanks Lauren Thomas and Lara Lewellyn for expert technical assistance. Drosophila work was supported by National Institute on Alcohol Abuse and Alcoholism grants P20 AA017828 and R01 AA020634 to MG and MFM. JCB, AGD, LDM, RCR, and JTA were supported by National Institute on Alcohol Abuse and Alcoholism grants P20 AA017828 to AGD and JCB and R01 AA016837 to JCB. Some strains were provided by the Caenorhabditis Genetics Center (CGC), which is funded by the NIH Office of Research Infrastructure Programs grant P40 OD010440. MFM was supported by P20 AA017828 and R01 AA020634. VIV, MM, GOM, and VSW were supported by R21 AA022749.

Collaborative Study of the Genetics of Alcoholism (COGA): Victor Hesselbrock, Lance Bauer, Grace Chan, Howard J. Edenberg, Xiaoling Xuei, John Nurnberger Jr, Sean O'Connor, Tatiana Foroud, Daniel L. Koller, Leah Wetherill, Samuel Kuperman, John Kramer, Bernice Porjesz, Sun J. Kang, Niklas Manz, Madhavi Rangaswamy, Laura Bierut, John Rice, Kathleen Bucholz, John W. Rohrbaugh, Jen C. Wang, Alison Goate, Marc Schuckit, Jay Tischfield, Andrew Brooks, Laura Almasy, Robert E. Taylor, Danielle M. Dick.

German Study of the Genetics of Addictions (GESGA): Josef Frank, MSc, Sven Cichon, PhD, Jens Treutlein, PhD, Monika Ridinger, MD, Manuel Mattheisen, MD, Per Hoffmann, PhD, Stefan Herms, MSc, Norbert Wodarz, MD, Michael Soyka, MD, Peter Zill, PhD, Wolfgang Maier, MD, Rainald Mössner, MD, Franziska Degenhardt, MD, Wolfgang Gaebel, MD, Norbert Dahmen, MD, Norbert Scherbaum, MD, Christine Schmäl, MD, Michael Steffens, MD, Susanne Lucae, MD, Marcus Ising, MD, Bertram MüllerMyhsok, MD, Markus M. Nöthen, MD, Karl Mann, MD, Falk Kiefer, MD, and Marcella Rietschel, MD.

\section{AUTHOR CONTRIBUTIONS}

BPR conceived and designed the study, acquired funding, organized replication, and wrote the manuscript with AEA and LMH. AEA and LMH organized the study and performed primary analyses of the data; TBB performed imputation with assistance from FA for imputation of COGA data; access to COGA data was provided by DMD; AM undertook QC analyses; BTW oversaw data cleaning, QC, imputation, and analysis of genotypic data with assistance from BSM and SAB. VSW, GOM, MM, and VIV undertook bioinformatic and postmortem brain studies of LOC339975. ACE performed geneset enrichment analysis. RCR, JTA, GGB, LDM, AGD, and JCB undertook C. elegans studies. MFM and BPR performed GeneNetwork analyses of archival BXD mouse data. RFC, PB, and MG undertook Drosophila studies. RSP, BR, and MSB undertook dantrolene studies in rats. DGP, DW, CAP, and KSK organized the collection of samples in Ireland and Northern Ireland. The COGA Consortium, JBW, GZ, GWM, AKH, NGM, ACH, and PAFM (for the OZALC Consortium), JF, MR, NW, MS, PZ, MI, MMN, FK, MR, and the GESGA 
Consortium, and JG, RS, RK, LA, HZ, HRK, and LAF (for the Yale/UPenn Consortium) provided access to their sample data for replication. All authors contributed to and approved the final manuscript.

\section{FINANCIAL DISCLOSURES}

M. Ridinger received compensation from Lundbeck Switzerland and the Lundbeck Institute for advisory boards and expert meetings and from Lundbeck and Lilly Suisse for workshops and presentations. N. Wodarz has received speaker's honoraria and travel funds from Janssen-Cilag and Essex Pharma. He took part in industry sponsored multicenter randomized trials by D\&A Pharma and Lundbeck. H. R. Kranzler has been a consultant or advisory board member for Alkermes, Lilly, Lundbeck, Pfizer, and Roche. He is also a member of the American Society of Clinical Psychopharmacology's Alcohol Clinical Trials Initiative, which is supported by AbbVie, Alkermes, Ethypharm, Lilly, Lundbeck, and Pfizer. Except as noted above, all other authors report no biomedical financial interests or potential conflicts of interest.

\section{ONLINE RESOURCES}

Trinity College Biobank: http://www.tcd.ie/IMM/trinitybiobank/; accessed June, 2011.

1000 Genomes Project: http://www.1000genomes.org; accessed April, 2016.

GWAS3D: http://jjwanglab.org/gwas3d/gwas3d/gwas3d/ welcome; accessed August, 2016.

Mouse Genome Informatics: http://www.informatics.jax. org; accessed February, 2016.

GeneNetwork: http://www.genenetwork.org/webqtl/main. py; accessed February, 2016.

New South Wales Tissue Resource Centre: http://sydney. edu.au/medicine/pathology/trc; accessed December, 2014.

\section{REFERENCES}

Alaimo JT, Davis SJ, Song SS, Burnette CR, Grotewiel M, Shelton KL, Pierce-Shimomura JT, Davies AG, Bettinger JC (2012) Ethanol metabolism and osmolarity modify behavioral responses to ethanol in C. elegans. Alcohol Clin Exp Res 36:1840-1850.

Alam T, Medvedeva YA, Jia H, Brown JB, Lipovich L, Bajic VB (2014) Promoter analysis reveals globally differential regulation of human long noncoding RNA and protein-coding genes. PLoS One 9:e109443.

American Psychiatric Association (1994) Diagnostic and Statistical Manual of Mental Disorders, 4th ed. American Psychiatric Association, Washington, DC.

Atsma F, Veldhuizen I, de Vegt F, Doggen C, de Kort W (2011) Cardiovascular and demographic characteristics in whole blood and plasma donors: results from the Donor InSight study. Transfusion 51:412-420.

Aulchenko YS, Ripke S, Isaacs A, van Duijn CM (2007) GenABEL: an R library for genome-wide association analysis. Bioinformatics 23:1294 1296.

Bahi A, Dreyer JL (2012) Involvement of tissue plasminogen activator "tPA" in ethanol-induced locomotor sensitization and conditioned-place preference. Behav Brain Res 226:250-258.
Baik I, Cho NH, Kim SH, Han BG, Shin C (2011) Genome-wide association studies identify genetic loci related to alcohol consumption in Korean men. Am J Clin Nutr 93:809-816.

Bargmann CI (1998) Neurobiology of the Caenorhabditis elegans genome. Science 282:2028-2033.

Barry G, Briggs JA, Hwang DW, Nayler SP, Fortuna PR, Jonkhout N, Dachet F, Maag JL, Mestdagh P, Singh EM, Avesson L, Kaczorowski DC, Ozturk E, Jones NC, Vetter I, Arriola-Martinez L, Hu J, Franco GR, Warn VM, Gong A, Dinger ME, Rigo F, Lipovich L, Morris MJ, O'Brien TJ, Lee DS, Loeb JA, Blackshaw S, Mattick JS, Wolvetang EJ (2017) The long non-coding RNA NEAT1 is responsive to neuronal activity and is associated with hyperexcitability states. Sci Rep 7:40127.

Barry G, Briggs JA, Vanichkina DP, Poth EM, Beveridge NJ, Ratnu VS, Nayler SP, Nones K, Hu J, Bredy TW, Nakagawa S, Rigo F, Taft RJ, Cairns MJ, Blackshaw S, Wolvetang EJ, Mattick JS (2014) The long noncoding RNA Gomafu is acutely regulated in response to neuronal activation and involved in schizophrenia-associated alternative splicing. Mol Psychiatry 19:486-494.

Bergeson SE, Kyle Warren R, Crabbe JC, Metten P, Gene Erwin V, Belknap JK (2003) Chromosomal loci influencing chronic alcohol withdrawal severity. Mamm Genome 14:454-463.

Bettinger JC, Leung K, Bolling MH, Goldsmith AD, Davies AG (2012) Lipid environment modulates the development of acute tolerance to ethanol in Caenorhabditis elegans. PLoS One 7:e35192.

Bhandari P, Hill JS, Farris SP, Costin B, Martin I, Chan CL, Alaimo JT, Bettinger JC, Davies AG, Miles MF, Grotewiel M (2012) Chloride intracellular channels modulate acute ethanol behaviors in Drosophila, Caenorhabditis elegans and mice. Genes Brain Behav 11:387-397.

Bond J, Ye Y, Cherpitel CJ, Room R, Rehm J, Borges G, Cremonte M, Gmel G, Hao W, Sovinova H, Stockwell T (2010) The relationship between self-reported drinking and BAC level in emergency room injury cases: is it a straight line? Alcohol Clin Exp Res 34:1118-1125.

Brenner S (1974) The genetics of Caenorhabditis elegans. Genetics 77:71-94.

Browning BL, Yu Z (2009) Simultaneous genotype calling and haplotype phasing improves genotype accuracy and reduces false-positive associations for genome-wide association studies. Am J Hum Genet 85:847-861.

Brownlee DJ, Fairweather I (1999) Exploring the neurotransmitter labyrinth in nematodes. Trends Neurosci 22:16-24.

Bucholz KK, Cadoret R, Cloninger CR, Dinwiddie SH, Hesselbrock VM, Nurnberger JI Jr, Reich T, Schmidt I, Schuckit MA (1994) A new, semistructured psychiatric interview for use in genetic linkage studies: a report on the reliability of the SSAGA. J Stud Alcohol 55:149-158.

Chan RF, Lewellyn L, DeLoyht JM, Sennett K, Coffman S, Hewitt M, Bettinger JC, Warrick JM, Grotewiel M (2014) Contrasting influences of Drosophila white/mini-white on ethanol sensitivity in two different behavioral assays. Alcohol Clin Exp Res 38:1582-1593.

Cotton NS (1979) The familial incidence of alcoholism: a review. J Stud Alcohol 40:89-116.

Crabbe JC (2002) Alcohol and genetics: new models. Am J Med Genet 114:969-974.

Davies AG, Bettinger JC, Thiele TR, Judy ME, McIntire SL (2004) Natural variation in the npr-1 gene modifies ethanol responses of wild strains of $C$. elegans. Neuron 42:731-743.

Davies AG, Pierce-Shimomura JT, Kim H, VanHoven MK, Thiele TR, Bonci A, Bargmann CI, McIntire SL (2003) A central role of the BK potassium channel in behavioral responses to ethanol in C. elegans. Cell 115:655-666.

Edenberg HJ, Koller DL, Xuei X, Wetherill L, McClintick JN, Almasy L, Bierut LJ, Bucholz KK, Goate A, Aliev F, Dick D, Hesselbrock V, Hinrichs A, Kramer J, Kuperman S, Nurnberger JI Jr, Rice JP, Schuckit MA, Taylor R, Todd Webb B, Tischfield JA, Porjesz B, Foroud T (2010) Genome-wide association study of alcohol dependence implicates a region on chromosome 11. Alcohol Clin Exp Res 34:840-852.

Faghihi MA, Modarresi F, Khalil AM, Wood DE, Sahagan BG, Morgan TE, Finch CE, St Laurent G 3rd, Kenny PJ, Wahlestedt C (2008) Expression of a noncoding RNA is elevated in Alzheimer's disease and drives rapid feed-forward regulation of beta-secretase. Nat Med 14:723-730. 
Frank J, Cichon S, Treutlein J, Ridinger M, Mattheisen M, Hoffmann P, Herms S, Wodarz N, Soyka M, Zill P, Maier W, Mossner R, Gaebel W, Dahmen N, Scherbaum N, Schmal C, Steffens M, Lucae S, Ising M, Muller-Myhsok B, Nothen MM, Mann K, Kiefer F, Rietschel M (2012) Genome-wide significant association between alcohol dependence and a variant in the ADH gene cluster. Addict Biol 17:171-180.

French RL, Heberlein U (2009) Glycogen synthase kinase-3/Shaggy mediates ethanol-induced excitotoxic cell death of Drosophila olfactory neurons. Proc Natl Acad Sci U S A 106:20924-20929.

Gass JT, Olive MF (2008) Glutamatergic substrates of drug addiction and alcoholism. Biochem Pharmacol 75:218-265.

Gelernter J, Kranzler HR, Sherva R, Almasy L, Koesterer R, Smith AH, Anton R, Preuss UW, Ridinger M, Rujescu D, Wodarz N, Zill P, Zhao H, Farrer LA (2014) Genome-wide association study of alcohol dependence: significant findings in African- and European-Americans including novel risk loci. Mol Psychiatry 19:41-49.

Genomes Project Consortium (2010) A map of human genome variation from population-scale sequencing. Nature 467:1061-1073.

Grotewiel M, Bettinger JC (2015) Drosophila and Caenorhabditis elegans as discovery platforms for genes involved in human alcohol use disorder. Alcohol Clin Exp Res 39:1292-1311.

Guttman M, Donaghey J, Carey BW, Garber M, Grenier JK, Munson G, Young G, Lucas AB, Ach R, Bruhn L, Yang X, Amit I, Meissner A, Regev A, Rinn JL, Root DE, Lander ES (2011) lincRNAs act in the circuitry controlling pluripotency and differentiation. Nature 477:295-300.

Hangauer MJ, Vaughn IW, McManus MT (2013) Pervasive transcription of the human genome produces thousands of previously unidentified long intergenic noncoding RNAs. PLoS Genet 9:e1003569.

Harford TC, Chen CM, Saha TD, Smith SM, Ruan WJ, Grant BF (2013) DSM-IV personality disorders and associations with externalizing and internalizing disorders: results from the National Epidemiologic Survey on Alcohol and Related Conditions. J Psychiatr Res 47:1708-1716.

Hasin DS, Stinson FS, Ogburn E, Grant BF (2007) Prevalence, correlates, disability, and comorbidity of DSM-IV alcohol abuse and dependence in the United States: results from the National Epidemiologic Survey on Alcohol and Related Conditions. Arch Gen Psychiatry 64:830-842.

Heath AC, Whitfield JB, Martin NG, Pergadia ML, Goate AM, Lind PA, McEvoy BP, Schrage AJ, Grant JD, Chou YL, Zhu R, Henders AK, Medland SE, Gordon SD, Nelson EC, Agrawal A, Nyholt DR, Bucholz KK, Madden PA, Montgomery GW (2011) A quantitative-trait genomewide association study of alcoholism risk in the community: findings and implications. Biol Psychiatry 70:513-518.

Howie BN, Donnelly P, Marchini J (2009) A flexible and accurate genotype imputation method for the next generation of genome-wide association studies. PLoS Genet 5:e1000529.

Johnson AD, Handsaker RE, Pulit SL, Nizzari MM, O'Donnell CJ, de Bakker PI (2008) SNAP: a web-based tool for identification and annotation of proxy SNPs using HapMap. Bioinformatics 24:2938-2939.

Joslyn G, Ravindranathan A, Brush G, Schuckit M, White RL (2010) Human variation in alcohol response is influenced by variation in neuronal signaling genes. Alcohol Clin Exp Res 34:800-812.

Kaletta T, Hengartner MO (2006) Finding function in novel targets: C. elegans as a model organism. Nat Rev Drug Discov 5:387-398.

Kamath RS, Martinez-Campos M, Zipperlen P, Fraser AG, Ahringer J (2001) Effectiveness of specific RNA-mediated interference through ingested double-stranded RNA in Caenorhabditis elegans. Genome Biol 2: RESEARCH0002.

Kapfhamer D, Bettinger JC, Davies AG, Eastman CL, Smail EA, Heberlein U, McIntire SL (2008) Loss of RAB-3/A in Caenorhabditis elegans and the mouse affects behavioral response to ethanol. Genes Brain Behav 7:669676.

Kendler KS, Chen X, Dick D, Maes H, Gillespie N, Neale MC, Riley B (2012) Recent advances in the genetic epidemiology and molecular genetics of substance use disorders. Nat Neurosci 15:181-189.

Kerin T, Ramanathan A, Rivas K, Grepo N, Coetzee GA, Campbell DB (2012) A noncoding RNA antisense to moesin at 5p14.1 in autism. Sci Transl Med 4:128ra140.
Kirstein SL, Davidson KL, Ehringer MA, Sikela JM, Erwin VG, Tabakoff B (2002) Quantitative trait loci affecting initial sensitivity and acute functional tolerance to ethanol-induced ataxia and brain cAMP signaling in BXD recombinant inbred mice. J Pharmacol Exp Ther 302:1238-1245.

Kuo PH, Neale MC, Riley BP, Webb BT, Sullivan PF, Vittum J, Patterson DG, Thiselton DL, van den Oord EJ, Walsh D, Kendler KS, Prescott CA (2006) Identification of susceptibility loci for alcohol-related traits in the Irish-affected sib pair study of alcohol dependence. Alcohol Clin Exp Res 30:1801-1816.

Kurokawa K, Mizuno K, Ohkuma S (2013) Dopamine D1 receptor signaling system regulates ryanodine receptor expression in ethanol physical dependence. Alcohol Clin Exp Res 37:771-783.

Kurokawa K, Mizuno K, Shibasaki M, Ohkuma S (2010) Regulation of ryanodine receptors by dopamine D1 receptors during methamphetamineinduced place conditioning. J Neurochem 115:1206-1214.

Kurokawa K, Mizuno K, Shibasaki M, Ohkuma S (2011) Dopamine D(1) receptors participate in cocaine-induced place preference via regulation of ryanodine receptor expression. J Pharmacol Sci 117:87-97.

Li MJ, Wang LY, Xia Z, Sham PC, Wang J (2013) GWAS3D: detecting human regulatory variants by integrative analysis of genome-wide associations, chromosome interactions and histone modifications. Nucleic Acids Res 41:W150-W158.

Lifshitz LM, Carmichael JD, Lai FA, Sorrentino V, Bellve K, Fogarty KE, ZhuGe R (2011) Spatial organization of RYRs and BK channels underlying the activation of STOCs by $\mathrm{Ca}(2+)$ sparks in airway myocytes. J Gen Physiol 138:195-209.

Liu J, Vaithianathan T, Manivannan K, Parrill A, Dopico AM (2008) Ethanol modulates $\mathrm{BKCa}$ channels by acting as an adjuvant of calcium. Mol Pharmacol 74:628-640.

Lubbers BR, Smit AB, Spijker S, van den Oever MC (2014) Neural ECM in addiction, schizophrenia, and mood disorder. Prog Brain Res 214:263284.

Martin GE, Hendrickson LM, Penta KL, Friesen RM, Pietrzykowski AZ, Tapper AR, Treistman SN (2008) Identification of a BK channel auxiliary protein controlling molecular and behavioral tolerance to alcohol. Proc Natl Acad Sci U S A 105:17543-17548.

Mathies LD, Blackwell GG, Austin MK, Edwards AC, Riley BP, Davies AG, Bettinger JC (2015) SWI/SNF chromatin remodeling regulates alcohol response behaviors in Caenorhabditis elegans and is associated with alcohol dependence in humans. Proc Natl Acad Sci U S A 112: 3032-3037.

Matthews DJ, Kopczynski J (2001) Using model-system genetics for drugbased target discovery. Drug Discov Today 6:141-149.

Mercer TR, Dinger ME, Sunkin SM, Mehler MF, Mattick JS (2008) Specific expression of long noncoding RNAs in the mouse brain. Proc Natl Acad Sci U S A 105:716-721.

Metten P, Phillips TJ, Crabbe JC, Tarantino LM, McClearn GE, Plomin R, Erwin VG, Belknap JK (1998) High genetic susceptibility to ethanol withdrawal predicts low ethanol consumption. Mamm Genome 9:983-990.

Park BL, Kim JW, Cheong HS, Kim LH, Lee BC, Seo CH, Kang T-C, Nam Y-W, Kim G-B, Shin HD, Choi I-G (2013) Extended genetic effects of ADH cluster genes on the risk of alcohol dependence: from GWAS to replication. Hum Genet 132:657-668.

Pawlak R, Melchor JP, Matys T, Skrzypiec AE, Strickland S (2005) Ethanol-withdrawal seizures are controlled by tissue plasminogen activator via modulation of NR2B-containing NMDA receptors. Proc Natl Acad Sci U S A 102:443-448.

Philip VM, Duvvuru S, Gomero B, Ansah TA, Blaha CD, Cook MN, Hamre KM, Lariviere WR, Matthews DB, Mittleman G, Goldowitz D, Chesler EJ (2010) High-throughput behavioral phenotyping in the expanded panel of BXD recombinant inbred strains. Genes Brain Behav 9:129-159.

Phillips TJ, Crabbe JC, Metten P, Belknap JK (1994) Localization of genes affecting alcohol drinking in mice. Alcohol Clin Exp Res 18:931-941.

Prescott CA, Caldwell CB, Carey G, Vogler GP, Trumbetta SL, Gottesman II (2005a) The Washington University Twin Study of alcoholism. Am J Med Genet B Neuropsychiatr Genet 134:48-55. 
Prescott CA, Sullivan PF, Myers JM, Patterson DG, Devitt M, Halberstadt LJ, Walsh D, Kendler KS (2005b) The Irish Affected Sib Pair Study of Alcohol Dependence: study methodology and validation of diagnosis by interview and family history. Alcohol Clin Exp Res 29:417-429.

Quillen EE, Chen XD, Almasy L, Yang F, He H, Li X, Wang XY, Liu TQ, Hao W, Deng HW, Kranzler HR, Gelernter J (2014) ALDH2 is associated to alcohol dependence and is the major genetic determinant of "daily maximum drinks" in a GWAS study of an isolated rural Chinese sample. Am J Med Genet B Neuropsychiatr Genet 165B:103-110.

Rice DP (1999) Economic costs of substance abuse, 1995. Proc Assoc Am Physicians 111:119-125.

Riley B, Thiselton D, Maher BS, Bigdeli T, Wormley B, McMichael GO, Fanous AH, Vladimirov V, O'Neill FA, Walsh D, Kendler KS (2010) Replication of association between schizophrenia and ZNF804A in the Irish Case-Control Study of Schizophrenia sample. Mol Psychiatry 15:2937.

Roberts TC, Morris KV, Wood MJ (2014) The role of long non-coding RNAs in neurodevelopment, brain function and neurological disease. Philos Trans R Soc Lond B Biol Sci 369. doi: 10.1098/rstb.2013.0507.

Schuckit MA, Tipp JE, Smith TL, Wiesbeck GA, Kalmijn J (1997) The relationship between self-rating of the effects of alcohol and alcohol challenge results in ninety-eight young men. J Stud Alcohol 58:397404.

Schuierer M, Hilger-Eversheim K, Dobner T, Bosserhoff AK, Moser M, Turner J, Crossley M, Buettner R (2001) Induction of AP-2alpha expression by adenoviral infection involves inactivation of the AP-2rep transcriptional corepressor CtBP1. J Biol Chem 276:27944-27949.

Schumann G, Coin LJ, Lourdusamy A, Charoen P, Berger KH, Stacey D, Desrivieres S, Aliev FA, Khan AA, Amin N, Aulchenko YS, Bakalkin G, Bakker SJ, Balkau B, Beulens JW, Bilbao A, de Boer RA, Beury D, Bots ML, Breetvelt EJ, Cauchi S, Cavalcanti-Proenca C, Chambers JC, Clarke TK, Dahmen N, de Geus EJ, Dick D, Ducci F, Easton A, Edenberg HJ, Esko T, Fernandez-Medarde A, Foroud T, Freimer NB, Girault JA, Grobbee DE, Guarrera S, Gudbjartsson DF, Hartikainen AL, Heath AC, Hesselbrock V, Hofman A, Hottenga JJ, Isohanni MK, Kaprio J, Khaw KT, Kuehnel B, Laitinen J, Lobbens S, Luan J, Mangino M, Maroteaux M, Matullo G, McCarthy MI, Mueller C, Navis G, Numans ME, Nunez A, Nyholt DR, Onland-Moret CN, Oostra BA, O'Reilly PF, Palkovits M, Penninx BW, Polidoro S, Pouta A, Prokopenko I, Ricceri F, Santos E, Smit JH, Soranzo N, Song K, Sovio U, Stumvoll M, Surakk I, Thorgeirsson TE, Thorsteinsdottir U, Troakes C, Tyrfingsson T, Tonjes A, Uiterwaal CS, Uitterlinden AG, van der Harst P, van der Schouw YT, Staehlin O, Vogelzangs N, Vollenweider P, Waeber G, Wareham NJ, Waterworth DM, Whitfield JB, Wichmann EH, Willemsen G, Witteman JC, Yuan X, Zhai G, Zhao JH, Zhang W, Martin NG, Metspalu A, Doering A, Scott J, Spector TD, Loos RJ, Boomsma DI, Mooser V, Peltonen L, Stefansson K, van Duijn CM, Vineis P, Sommer WH, Kooner JS, Spanagel R, Heberlein UA, Jarvelin MR, Elliott P (2011) Genome-wide association and genetic functional studies identify autism susceptibility candidate 2 gene (AUTS2) in the regulation of alcohol consumption. Proc Natl Acad Sci U S A 108:7119-7124.

Sigvardsson S, Bohman M, Cloninger CR (1996) Replication of the Stockholm Adoption Study of alcoholism. Confirmatory cross-fostering analysis. Arch Gen Psychiatry 53:681-687.

Smith AW, Nealey KA, Wright JW, Walker BM (2011) Plasticity associated with escalated operant ethanol self-administration during acute withdrawal in ethanol-dependent rats requires intact matrix metalloproteinase systems. Neurobiol Learn Mem 96:199-206.

Storey JD, Tibshirani R (2003) Statistical significance for genomewide studies. Proc Natl Acad Sci U S A 100:9440-9445.

Thornton T, McPeek MS (2007) Case-control association testing with related individuals: a more powerful quasi-likelihood score test. Am J Hum Genet 81:321-337.

Treutlein J, Cichon S, Ridinger M, Wodarz N, Soyka M, Zill P, Maier W, Moessner R, Gaebel W, Dahmen N, Fehr C, Scherbaum N, Steffens M, Ludwig KU, Frank J, Wichmann HE, Schreiber S, Dragano N, Sommer
WH, Leonardi-Essmann F, Lourdusamy A, Gebicke-Haerter P, Wienker TF, Sullivan PF, Nothen MM, Kiefer F, Spanagel R, Mann K, Rietschel M (2009) Genome-wide association study of alcohol dependence. Arch Gen Psychiatry 66:773-784.

Volkow ND, Wang GJ, Fowler JS, Tomasi D (2012) Addiction circuitry in the human brain. Annu Rev Pharmacol Toxicol 52:321-336.

Wang JC, Foroud T, Hinrichs AL, Le NX, Bertelsen S, Budde JP, Harari O, Koller DL, Wetherill L, Agrawal A, Almasy L, Brooks AI, Bucholz K, Dick D, Hesselbrock V, Johnson EO, Kang S, Kapoor M, Kramer J, Kuperman S, Madden PA, Manz N, Martin NG, McClintick JN, Montgomery GW, Nurnberger JI Jr, Rangaswamy M, Rice J, Schuckit M, Tischfield JA, Whitfield JB, Xuei X, Porjesz B, Heath AC, Edenberg HJ, Bierut LJ, Goate AM (2013) A genome-wide association study of alcoholdependence symptom counts in extended pedigrees identifies C15orf53. Mol Psychiatry 18:1218-1224.

Wang X, Pandey AK, Mulligan MK, Williams EG, Mozhui K, Li Z, Jovaisaite V, Quarles LD, Xiao Z, Huang J, Capra JA, Chen Z, Taylor WL, Bastarache L, Niu X, Pollard KS, Ciobanu DC, Reznik AO, Tishkov AV, Zhulin IB, Peng J, Nelson SF, Denny JC, Auwerx J, Lu L, Williams RW (2016) Joint mouse-human phenome-wide association to test gene function and disease risk. Nat Commun 7:10464.

Wellcome Trust Case Control Consortium (2007) Genome-wide association study of 14,000 cases of seven common diseases and 3,000 shared controls. Nature 447:661-678.

Willer CJ, Li Y, Abecasis GR (2010) METAL: fast and efficient meta-analysis of genomewide association scans. Bioinformatics 26:2190-2191.

Wolen AR, Phillips CA, Langston MA, Putman AH, Vorster PJ, Bruce NA, York TP, Williams RW, Miles MF (2012) Genetic dissection of acute ethanol responsive gene networks in prefrontal cortex: functional and mechanistic implications. PLoS One 7:e33575.

Ystrom E, Reichborn-Kjennerud T, Aggen SH, Kendler KS (2011) Alcohol dependence in men: reliability and heritability. Alcohol Clin Exp Res 35:1716-1722.

\section{SUPPORTING INFORMATION}

Additional Supporting Information may be found online in the supporting information tab for this article:

Appendix S1. Supplementary information.

Fig. S1. GWAS data QC processes.

Fig. S2. Impact of BeagleCall on pre-imputation genotypic data quality.

Fig. S3. Post-QC Ancestry Analysis using MDS.

Fig. S4. Power of the post-QC sample of 706 AD cases and 1,748 controls.

Fig. S5. LocusZoom plots for additional loci with individual SNPs displaying $q<0.1$.

Fig. S6. GeneMania network derived from the set of 45 genes annotated for the 274 SNPs with $q<0.3$.

Fig. S7. Mutations in C. elegans orthologs of genes involved in calcium regulation cause EtOH response phenotypes.

Fig. S8. The $R y R$ locus and behavioral responses to $\mathrm{EtOH}$ in flies.

Fig. S9. Dantrolene dose dependently reduced the motivation to self-administer EtOH.

Table S1. All 274 SNPs with $q<0.3\left(p<1 \times 10^{-5}\right)$ in Irish AD GWAS discovery data with results of replication in 3 independent samples, and meta-analyses of independent case/control samples, all case control samples and all samples. 
Table S2. Lookup replication of AD genomewide association signals previously reported in samples of European descent.

Table S3. Results of gene-based analyses with KGG.

Table S4. Genetic interactions between associated loci identified in GENEMANIA network analysis.

Table S5. Results of iGSEA4GWAS analysis of signal over representation by functionally related sets of genes for 3 significant gene sets.
Table S6. Uncorrected basal speeds and 2-way ANOVA comparisons across time of EtOH exposure and genotype with Bonferroni post hoc comparisons at each time point. Development of AFT was tested using a paired 2-tailed $t$ test.

Table S7. Analysis of LOC339975 expression controlling for covariates in post mortem brain tissue. 